\title{
Feature-Based Jet Variability in the Upper Troposphere
}

\author{
Clemens SPensberger AND THOMAS SPENGLER \\ Geophysical Institute, University of Bergen, and Bjerknes Centre for Climate Research, Bergen, Norway
}

(Manuscript received 23 September 2019, in final form 22 May 2020)

\begin{abstract}
Jets in the upper troposphere constitute a cornerstone of both synoptic meteorology and climate dynamics, providing a direct link between weather and midlatitude climate variability. Conventionally, jet variability is often inferred indirectly through the variability of geopotential or sea level pressure. As recent findings pointed to physical discrepancies of this interpretation for the Southern Hemisphere, this study presents a global overview of jet variability based on automated jet detections in the upper troposphere. Consistent with previous studies, most ocean basins are dominated by variability patterns comprising either a latitudinal shift of the jet or a so-called pulsing, a broadening/narrowing of the jet distribution without a change in the mean position. Whereas previous studies generally associate a mode of storm track variability with either shifting or pulsing, jet-based variability patterns frequently represent a transition from shifting to pulsing, or vice versa, across the respective ocean basin. In the Northern Hemisphere, jet variability is consistent with geopotential variability, confirming earlier analyses. In the Southern Hemisphere, however, the variability of geopotential and jets often indicates different modes of variability. Notable exceptions are the consistent dominant modes of jet and geopotential variability in the South Pacific and, to a lesser extent, the south Indian Ocean during winter, as well as the dominant modes in the South Atlantic and south Indian Ocean during summer. Finally, tropical variability is shown to modulate the jet distribution in the Northern Hemisphere, which is in line with previous results. The response in the Southern Hemispheric, however, is shown to be markedly different.
\end{abstract}

\section{Introduction}

Jets in the upper troposphere signify regions of strong baroclinicity, a prerequisite for the development of extratropical cyclones (e.g., Lorenz 1955; Lindzen and Farrell 1980) and storm tracks (Chang et al. 2002; Wirth et al. 2018). Jets also demarcate the Rossby waveguide, as they are usually associated with strong gradients in potential vorticity (Hoskins and Ambrizzi 1993; Martius et al. 2010). In climate dynamics (e.g., Wallace and Gutzler 1981; Limpasuvan and Hartmann 1999), airice-sea interactions (e.g., Hall and Visbeck 2002), and paleoclimate (e.g., Van Meerbeeck et al. 2009), both the climatological state and its variability are most commonly inferred from time-mean geopotential. However, monthly and longer-term averages of geopotential do not capture weather events that define the location of the jet on shorter time scales (e.g., Fig. 4 of Spensberger et al. 2017). Further, Spensberger et al. (2020) documented that geopotential-based variability patterns are

\footnotetext{
Corresponding author: Clemens Spensberger, clemens.spensberger@ uib.no
}

largely independent from jet and storm track variability for several regions in the Southern Hemisphere. We thus present a global climatology of upper tropospheric jets and their variability based on a feature-based jet detection and compare our results to geopotential-based analyses for each ocean sector in both hemispheres.

Several jet detection schemes have been developed to investigate the synoptic evolution of weather systems and assess climate variability. Gallego et al. (2005) tracked selected circumpolar streamfunction contours in the Southern Hemisphere and associated these with the jet location. This procedure, however, does not account for the often zonally confined nature of the jet stream. Instead of focusing on contour lines, Koch et al. (2006) and Archer and Caldeira (2008) use a wind speed threshold to define jet bodies and track the occurrence of high wind events. Limbach et al. (2012) extend this approach to three dimensions, identifying jet volumes. While this approach allows for zonal discontinuities, jet bodies defined in this way typically encompass several to many distinct wind speed maxima. Consequently, jet bodies potentially mask essential features associated with internal flow structures. 

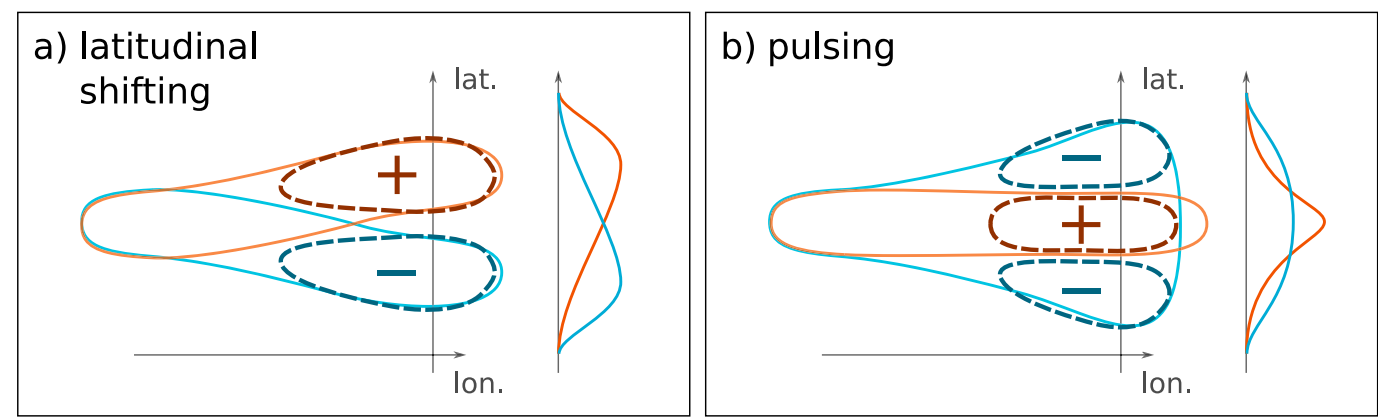

FIG. 1. Conceptual schematic of (a) latitudinal shifting and (b) pulsing-type jet variability based on the distribution of the location of the jet axis. Latitudinal shifting alternates the focus of the jet axis distribution (solid lines) relative to the climatological mean jet position, leading to a dipolar structure in the detection anomalies (dashdotted lines). In contrast, pulsing narrows/broadens the jet axis distribution without displacing its center latitudinally, leading to a tripole distribution centered around the climatological mean jet position.

Other schemes track meridional maxima of zonal wind, allowing for zonal discontinuities and highlighting key aspects of the flow structure (Manney et al. 2011; Pena-Ortiz et al. 2013; Manney et al. 2014, 2017). However, as they only consider wind maxima along meridians, their approach may underrepresent meridionally oriented jets, which frequently occur during Rossby wave breaking [cf. LC1 and LC2 in Thorncroft et al. (1993)]. For this reason, we base our analyses on the Spensberger et al. (2017) jet axis detection scheme, which is similar to that of Manney et al. (2014) but detects jets with no potential bias in their orientation.

Despite the availability of these automated jet detection schemes, jet variability is commonly characterized indirectly through, for example, the North Atlantic Oscillation (NAO), the Pacific-North America pattern (PNA), or the southern annular mode (SAM), which are based on the variability of geopotential or sea level pressure (e.g., Wallace and Gutzler 1981; Limpasuvan and Hartmann 1999). Using 700-hPa geopotential, Spensberger et al. (2020) however demonstrated that the connection between geopotential and jet variability fails for SAM. This finding is consistent with Thompson and Woodworth (2014), who demonstrated that eddy kinetic energy and the midlatitude meridional heat transport vary largely independently from SAM. Wettstein and Wallace (2010) and Athanasiadis et al. (2010) documented better correspondence between the eddy-covariance and geopotential-based perspectives for Northern Hemisphere variability, although their eddy-covariance-based results emphasize different aspects and regions of the storm track than geopotentialbased variability. Thus, geopotential variability does not necessarily describe the variability of the storm track or jets.

Based on the zonal-mean zonal wind over the North Atlantic and North Pacific, Eichelberger and Hartmann
(2007) and Li and Wettstein (2012) identified two dominant modes of month-to-month jet variability: first, a latitudinal shifting of the jet position, and second, a variation in strength without a change in location, which they refer to as pulsing of the jet. The respective dominance of either shifting or pulsing depends on the geographic separation between the eddy-driven and the subtropical jet (Eichelberger and Hartmann 2007) as well as the relative importance of internally driven variability ("eddy forcing") versus externally driven variability induced by the Hadley circulation ("tropical forcing") (Li and Wettstein 2012). While Wettstein and Wallace (2010) and Athanasiadis et al. (2010) confirmed these two types of variability in their analysis of eddy and geopotential variability, eddy-driven and subtropical jets are shown to be closely related dynamically (Lee and Kim 2003), and most jets display both characteristics to a varying degree (e.g., Manney et al. 2014). Further, it remains largely unclear how variability in the occurrence of jet features would project on the variability associated with these two jet archetypes.

A first step in establishing a link between geopotential and feature-based jet variability was taken by Strong and Magnusdottir (2008), using a jet body detection scheme similar to that of Koch et al. (2006). They, however, focus their analysis on a domain covering most of the Northern Hemisphere, and thereby likely entangle unrelated variability in the North Atlantic and North Pacific sectors (e.g., Ambaum et al. 2001). We extend their analysis to ocean sectors in both hemispheres, and complement their analysis by using jet axes instead of jet bodies.

Jet axes are well suited to capture the shifting and pulsing type variability. Latitudinal shifts in the jet location will be apparent as latitudinal displacements in the occurrence of jet axes (Fig. 1a). Further, Woollings et al. (2018) showed that strong jets predominantly 
occur close to their climatological mean position, whereas weaker jets generally exhibit pronounced meanders around that position (their Fig. 4). Variations in jet intensity would thus manifest themselves as a tripole pattern, in which jet detections are either concentrated on the climatological mean position or spread over a wider range of latitudes (Fig. 1b). Along the same lines, it has been proposed that an expected increase in socalled waviness (i.e., the amplitude of jet meanders) with global warming could be related to an increasing number of extreme events in the middle and high latitudes (Francis 2017, and references therein). Following these ideas, we first present a global climatology of the occurrence of jets, followed by systematically contrasting jet and geopotential variability for all ocean basins for both winter and summer.

\section{Data and methods}

We base our investigation on 6-hourly ERA-Interim reanalysis data for the period 1979-2018, interpolated onto a $0.5^{\circ} \times 0.5^{\circ}$ horizontal grid (Dee et al. 2011). We use the data on preinterpolated pressure levels and the \pm 2 -PVU surface (where $1 \mathrm{PVU}=10^{-6} \mathrm{~m}^{2} \mathrm{~s}^{-1} \mathrm{~K} \mathrm{~kg}^{-1}$ ), as provided by the European Centre for Medium-Range Weather Forecasts (ECMWF).

We detect jet axes using the algorithm of Spensberger et al. (2017) without modifications, where we use a detection threshold of $K=-5.5 \times 10^{-9} \mathrm{~s}^{-2}$ to identify well-defined wind maxima in the instantaneous wind field. As in Spensberger et al. (2017) we spectrally truncate the input wind field to T84 resolution. The algorithm separates areas of cyclonic and anticyclonic shear, thereby identifying both eddy-driven and subtropical jets as lines on the 2-PVU surface that is often referred to as the dynamical tropopause [see Spensberger et al. (2017) for details]. These shear-based jet axes thus also separate areas of different baroclinic life cycles (e.g., Davies et al. 1991) and regions of different types of wave breaking (Thorncroft et al. 1993; Rivière 2009; Barnes and Hartmann 2012).

Based on these jet detections, we construct timeaverage and composite "jet axis distributions" $\gamma$,

$$
\gamma=\frac{1}{A N} \sum_{i=1}^{N} l_{i},
$$

where $N$ is the number of time steps included in the average or composite, $A$ is the area covered by a grid cell, and $l_{i}$ denotes the length of a jet axis line, which is zero if no jet is detected, over the respective grid cell during time step $i$. With this procedure, jet axis distributions represent the average length of jet lines per unit area for a given time interval or composite.
We compare our climatological jet axis distribution with previously published climatologies based on alternative jet detections (Gallego et al. 2005; Koch et al. 2006; Manney et al. 2014), as well as cyclone tracks (Neu et al. 2013), and Rossby wave packets (Souders et al. 2014; Wirth et al. 2018). In this intercomparison, the Koch et al. (2006) scheme serves as a representative for all 2D and 3D jet body detection schemes and Manney et al. (2014) as a representative for all schemes based on meridional maxima of the zonal wind. We contrast the variability of the jet axis distribution with the variability of the occurrence of jet bodies [defined similarly to Koch et al. (2006)] in Strong and Davis (2008) and the variability of eddy-covariance-based diagnostics for the storm track (Chang et al. 2002). Such patterns have been reported for the Northern (Athanasiadis et al. 2010; Wettstein and Wallace 2010) and Southern Hemisphere (Thompson and Woodworth 2014).

\section{Jet stream climatology}

\section{a. Annual mean}

In both hemispheres, the annual mean jet axis distribution features a pair of poleward spiraling storm tracks winding around each other [Fig. 2; cf. Williams et al. (2007) for the Southern Hemisphere]. In both hemispheres, these spirals originate in the central subtropical Pacific and Atlantic, respectively. As part of these spirals, both hemispheres feature strong and zonally extended subtropical jets, extending from the Atlantic to the Pacific Ocean in the Northern Hemisphere and from the Indian to the Pacific Ocean in the Southern Hemisphere. Further, in both hemispheres, the subtropical and eddy-driven jet in the east Pacific merge over the American continent into one jet in the west Atlantic. These mergers suggest that the Atlantic sector can be influenced by disturbances originating in both the subtropical and the extratropical Pacific. The spiraliform structure also suggests a gradual transition from subtropical to eddy-driven jets (cf. Lee and Kim 2003; Manney et al. 2014).

Despite these symmetries, each hemisphere has distinctive features. For the Northern Hemisphere, for example, the Pacific jet displays a marked poleward tilt eastward of the date line in tandem with the emergence of a separate subtropical jet in the annual mean (Fig. 2a). Only the eastern North Atlantic, and to some extent the eastern North Pacific, feature a double-jet structure in the Northern Hemisphere (Fig. 2a). In the Southern Hemisphere, on the other hand, a double-jet structure is evident across the eastern South Atlantic, the entire Indian Ocean, and about the western two-thirds of the South Pacific (Fig. 2b). 

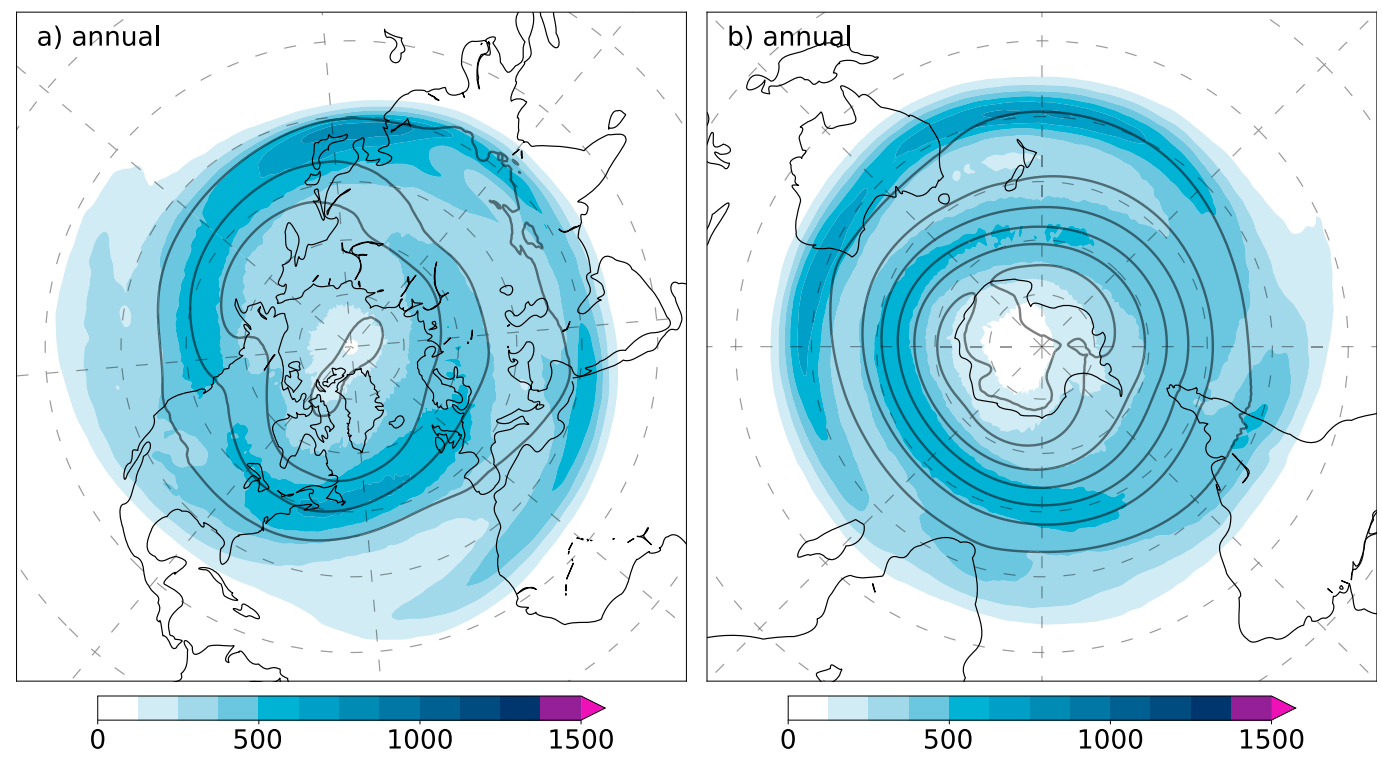

FIG. 2. Annual average jet axis distribution [average line length; $\mathrm{km}(1000 \mathrm{~km})^{-2}$ ] based on 6-hourly detections for the (a) Northern and (b) Southern Hemisphere. Light gray contours in both (a) and (b) show $700 \mathrm{hPa}$ geopotential height with a contour interval of $200 \mathrm{~m}$.

\section{b. Northern Hemisphere seasonality}

When interpreting the annual climatologies, it is important to keep in mind the large seasonal variability of the jet (e.g., Manney et al. 2014; Manney and Hegglin 2018). For example, the double-jet structures in the annual mean climatology for the Northern Hemisphere are only present during winter and spring in the North Atlantic (Figs. 3a,b), or spring and summer in the eastern North Pacific (Figs. 3b,c). The structure of the two interwoven spirals noted in the annual mean is apparent during all seasons (Fig. 3), but most pronounced during the transition seasons (MAM and SON; Figs. 3b,d). During winter, the Asian-Pacific jet is very zonal and only displays a poleward tilt in the east Pacific close to the North American coastline.

The jet detection schemes of Koch et al. (2006, their Fig. 4) and Manney et al. (2014, their Fig. 2) yield generally similar climatologies for the Northern Hemisphere, although the Koch et al. (2006) scheme yields a much more pronounced seasonal cycle with barely any detections during summer. This pronounced seasonality is most likely associated with an implicit bias of the scheme due to the wind speed threshold, which is exceeded much less frequently during summer than during winter. Due to the similarities between our scheme and that of Manney et al. (2014), the differences are less apparent. Nevertheless, Manney et al. (2014) consistently detect fewer jets near the termini of storm tracks. This difference is likely due to the under-representation of meridionally oriented jets in the Manney et al. (2014) scheme, which occur more frequently in these regions where cyclones reach the end of their baroclinic life cycle (Thorncroft et al. 1993).

Our jet climatology is also consistent with climatologies of storm-track diagnostics, such as bandpassfiltered geopotential variance (e.g., Fig. 2 of Chang et al. 2002). Disregarding jet detections at subtropical latitudes that are detached from the main storm track, the overall best agreement between our jet axis climatology and a variance-based metric is with the variance of upper-level meridional wind (Fig. 2b of Chang et al. 2002). However, these variance and covariance-based storm track metrics are mainly associated with the eddydriven jet and thereby omit signals that would be associated with the subtropical jet.

Comparing our jet climatologies to cyclone track densities (Neu et al. 2013, their Fig. 1) is challenging. First, Neu et al. (2013) report large differences in the cyclone track densities obtained for different tracking schemes. Second, the reported results tend to be rather noisy. Nevertheless, some differences between jets and cyclone tracks emerge for nearly all cyclone tracking schemes. Relative to our jet climatology, fewer cyclones are detected over land and in the vicinity of orography, whereas more cyclones are detected close to the termini of storm tracks as well as in higher latitudes. Consistent with variance-based storm track metrics, cyclone tracks mainly follow the eddy-driven jets and only few cyclones are detected at subtropical latitudes. 

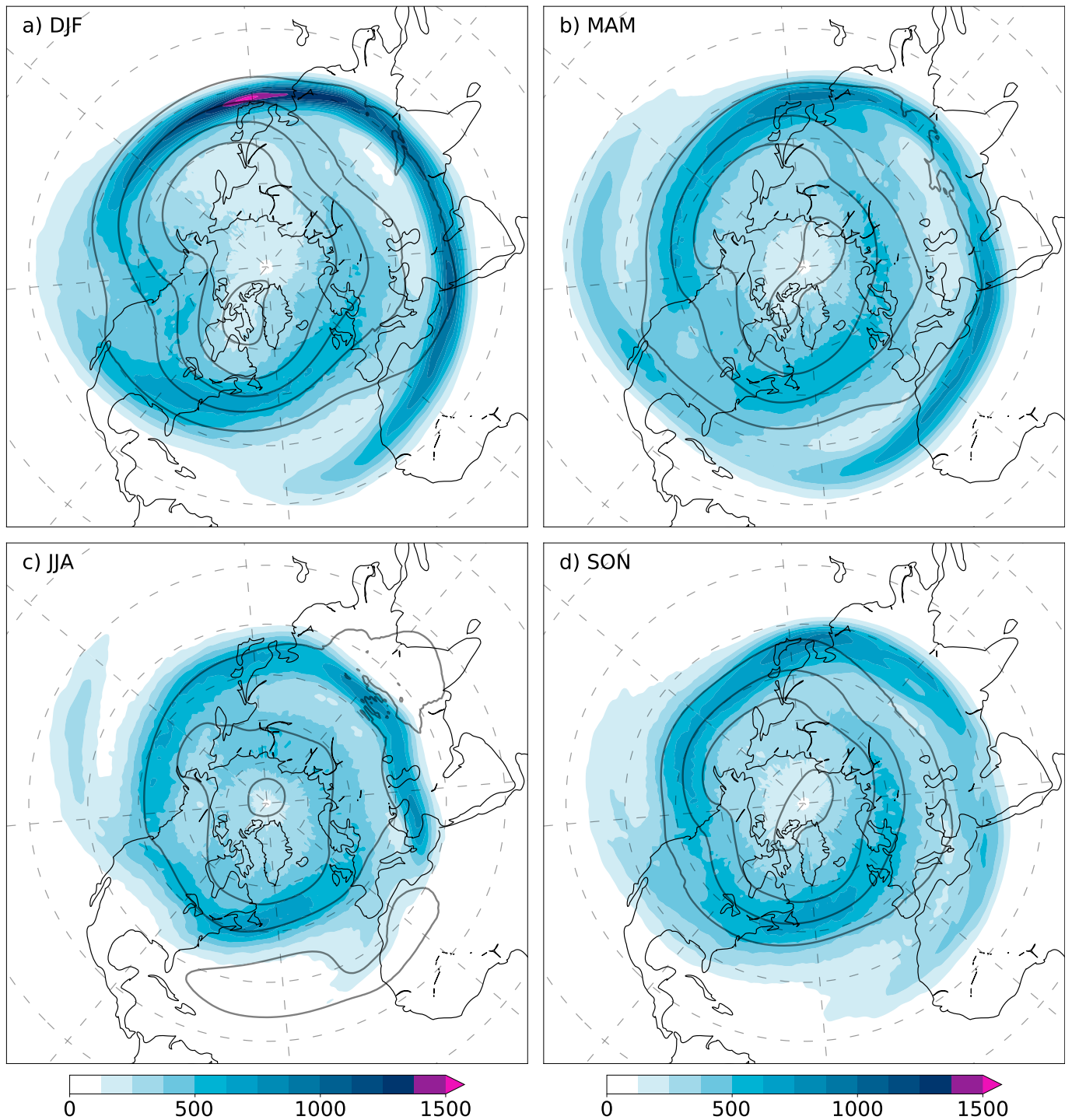

FIG. 3. Seasonal average jet axis distribution [average line length; $\mathrm{km}(1000 \mathrm{~km})^{-2}$ ] based on 6-hourly detections for the Northern Hemisphere in (a) DJF, (b) MAM, (c) JJA, and (d) SON. Light gray contours in (a)-(d) show 700 hPa-geopotential height with a contour interval of $200 \mathrm{~m}$.

Finally, we note a considerable difference between our seasonal jet climatology and the monthly average Rossby wave packet (RWP) activity (Fig. 5 of Souders et al. 2014). First, RWPs exhibit a pronounced seasonal cycle with hardly any RWP activity during July. Second, the contrast between detections over the ocean and continents is more pronounced for wave packets, with very little RWP activity over Asia. Third, the RWP activity is concentrated in comparatively zonal bands centered around $45^{\circ}-50^{\circ} \mathrm{N}$. Thus, the spiraliform structure and poleward tilt of the storm tracks are not reflected in the RWP perspective. With these considerable differences, RWPs might be the storm track diagnostic that our jet detections are least consistent with. This seems surprising, because, conceptually, the jet constitutes a waveguide to Rossby waves, such that RWPs should predominantly propagate along the jet.

An important difference between the RWP diagnostic and our jet detection is the use of time filtering. Souders et al. (2014) detect RWPs using a 30-day running average as mean state, such that one might expect these waves to propagate relative to the 30-day average waveguide. However, jet detections based on the monthly average winds in Fig. 4 of Spensberger et al. (2017) still show a spiraliform structure and frequent jets over the continents. It thus seems unlikely that the discrepancies between the RWP and the jet perspective on storm tracks arise solely because of the difference in time filtering. 

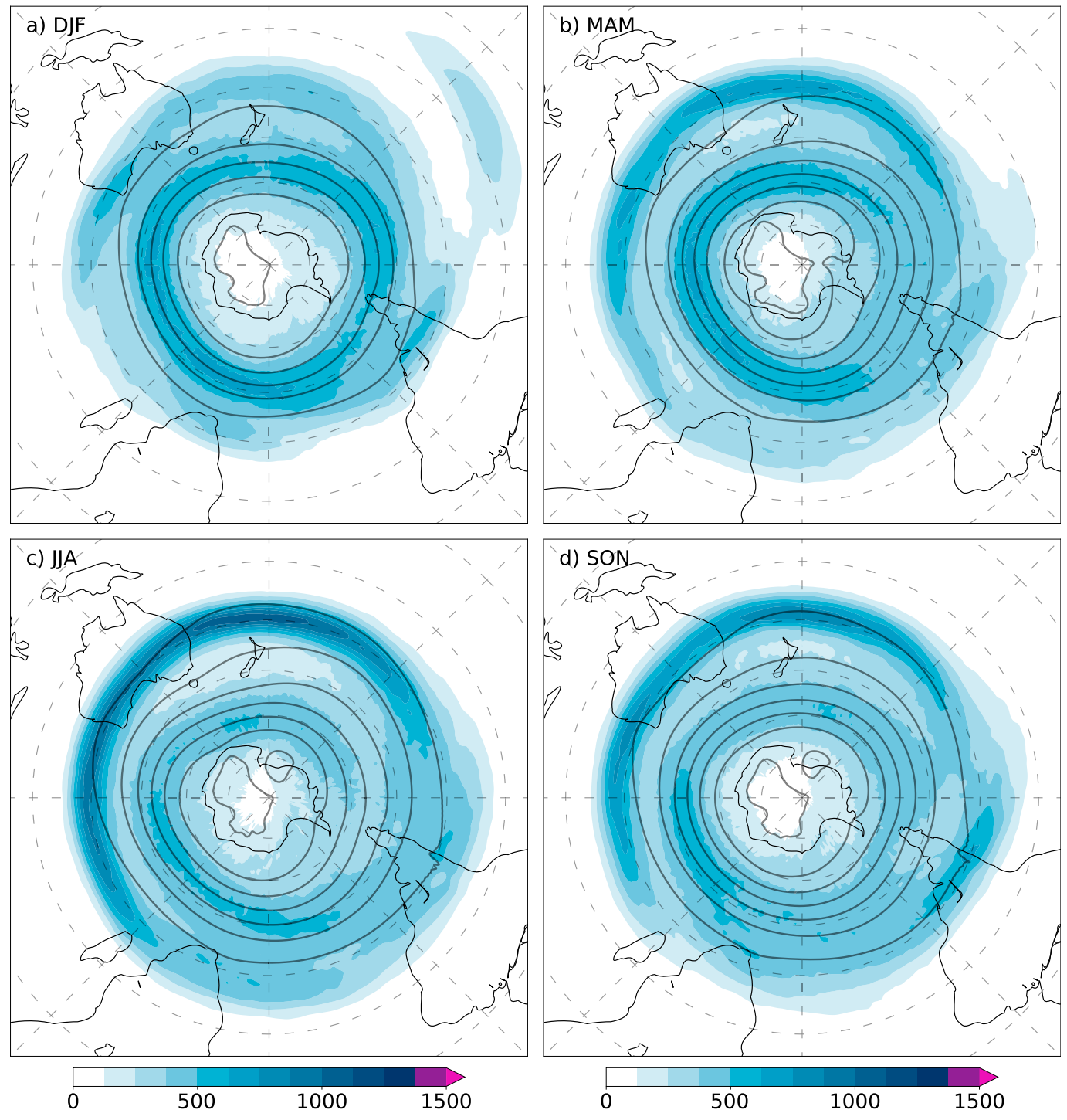

FIG. 4. As in Fig. 3, but for the Southern Hemisphere.

\section{c. Southern Hemisphere seasonality}

Compared to the Northern Hemisphere, the Southern Hemisphere jet axis distributions are more persistent throughout the seasons (Fig. 4). Similar to the annual mean, a pronounced subtropical jet covers most of the Indian Ocean and about the western two thirds of the South Pacific during austral autumn, winter, and spring (Figs. 4b-d). During austral summer, parts of the subtropical jet persist around Australia and New Zealand (Fig. 4a). These parts are accompanied by jet detections in the tropical South Pacific, which are associated with the "westerly duct" that has been documented in this region (Webster and Holton 1982; Hoskins and Ambrizzi 1993; Manney et al. 2014).
For all seasons, the Southern Hemisphere jet climatology shows a more zonal structure than its Northern Hemisphere counterpart (cf. Figs. 3 and 4). This zonality is particularly pronounced during austral summer (Fig. 4a), where the eddy driven jet displays a closed annular structure centered around Antarctica. During the other seasons, the storm track emerging over the subtropical east Pacific and in the lee of the Andes displays a marked poleward tilt throughout the South Atlantic and into the Indian Ocean. Double jet structures are common in the Indian Ocean and South Pacific during all seasons.

The streamline tracking algorithm of Gallego et al. (2005, their Fig. 5) yields a similar seasonal cycle. During summer, they identify the eddy-driven jet at the latitude 
TABLE 1. Correlation coefficients between the monthly NAO, EA, PNA, and WP indices provided by the Climate Prediction Center (CPC) of the National Oceanic and Atmospheric Administration (NOAA) and our geopotential ("Z") and jet axis-based ("JA") EOFs in the Atlantic ("Atl") and Pacific ("Pac") domains. Correlations interpreted as representing the same phenomenon are marked bold. Correlation coefficients below 0.3 have been omitted. All shown correlations are significant at the $99.9 \%$ level based on a two-tailed Student's $t$ test. All correlations are for winter.

\begin{tabular}{|c|c|c|c|c|c|c|c|c|}
\hline & Atl-Z1 & Atl-Z2 & Pac-Z1 & Pac-Z2 & Atl-JA1 & Atl-JA2 & Pac-JA1 & Pac-JA2 \\
\hline NAO & 0.84 & & & & 0.72 & & & \\
\hline EA & 0.37 & 0.74 & & & -0.32 & 0.61 & & \\
\hline WP & & & 0.63 & & & & 0.61 & \\
\hline PNA & & & & 0.77 & & & & 0.71 \\
\hline Atl-Z1 & & & 0.32 & & 0.64 & 0.52 & & \\
\hline Atl-Z2 & & & & & -0.56 & 0.65 & & \\
\hline Pac-Z1 & & & & & & & 0.86 & \\
\hline Pac-Z2 & & & & & & & & 0.66 \\
\hline
\end{tabular}

where we noted the annulus in Fig. 4a. During winter, they predominantly identify a double-jet structure, consistent with our detections in the Indian Ocean and South Pacific. Due to the limitations of detecting circumpolar streamlines, the Gallego et al. (2005) method does not capture the zonally asymmetric structure in the South Atlantic.

As in the Northern Hemisphere, our climatology is consistent with the results of Koch et al. (2006), Manney et al. (2014), and Neu et al. (2013). The Koch et al. (2006, their Fig. 5) scheme again displays a more pronounced seasonal cycle, the Manney et al. (2014, their Fig. 3) scheme shows a tendency for fewer jet detections near the termini of the storm tracks (e.g., the eastern South Pacific), and the Neu et al. (2013) intercomparison indicates a tendency for relatively more frequent cyclone detections at sub-Antarctic latitudes. In contrast to Koch et al. (2006), the Manney et al. (2014) scheme also detects jets in the so-called westerly duct. Opposite to the Northern Hemisphere, the RWP activity in the Southern Hemisphere is largely consistent with our jet detections (Fig. 6 of Souders et al. 2014). Both seasonal variations and zonal asymmetries are comparatively small and RWP activity is consistently located slightly equatorward of the eddy-driven jet in our climatologies.

\section{Jet stream variability}

We derive the intrinsic jet variability from the dominant EOFs of the monthly jet axis distribution for the different ocean sectors in both hemispheres. The monthly jet axis distributions are calculated following Eq. (1) in section 2. For the calculation of the EOF patterns, seasonal averages are removed and the standard deviation is scaled following the square root of the cosine of latitude to account for the convergence of the grid toward the poles.

Spensberger et al. (2020) demonstrated that geopotential variability does not necessarily align with jet- based variability. We thus contrast the dominant intrinsic modes of jet variability with geopotential variability and widely used variability indices for the Northern Hemisphere. Specifically, we use the monthly index time series for the NAO, the east Atlantic pattern (EA), the PNA, and the west Pacific pattern (WP) provided by the Climate Prediction Center (CPC) of the National Oceanic and Atmospheric Administration (NOAA), ${ }^{1}$ and refer to them as "canonical" variability indexes. For the Northern Hemisphere, Table 1 provides an overview of the correlation coefficients between the EOF patterns derived for this study and the respective canonical variability patterns.

For the Southern Hemisphere, the dominant variability pattern is called the Antarctic Oscillation (AAO), which is closely related to the SAM (Limpasuvan and Hartmann 1999). However, as Spensberger et al. (2020) found no significant relation between SAM and the jet axis distribution, we follow their recommendation and consider each ocean sector of the Southern Hemisphere independently. We will thus for the first time systematically present sector-specific geopotential and jet variability for the Southern Hemisphere.

We present both our jet-based and our geopotentialbased EOFs as regressions. The regression $\chi_{\text {reg }}$ of a variable $\chi$ against EOF $j$ of variable $\psi$ is calculated based on the instantaneous projection of $\psi$ on the EOF pattern. We calculate the regressed fields for a variable $\chi$

$$
\chi_{\mathrm{reg}}=\sum_{i=1}^{N}\left[\mathrm{EOF}_{j}(\psi) \psi_{i}\right] \chi_{i}
$$

where $i$ represents an index over all available time steps $N$ in the respective season and $\mathrm{EOF}_{j}(\psi)$ is the $j$ th spatial EOF pattern for a variable $\psi$. If $\chi_{i}$ is the "instantaneous

\footnotetext{
${ }^{1}$ See http://www.cpc.ncep.noaa.gov/products/precip/CWlink/pna/ nao.shtml.
} 

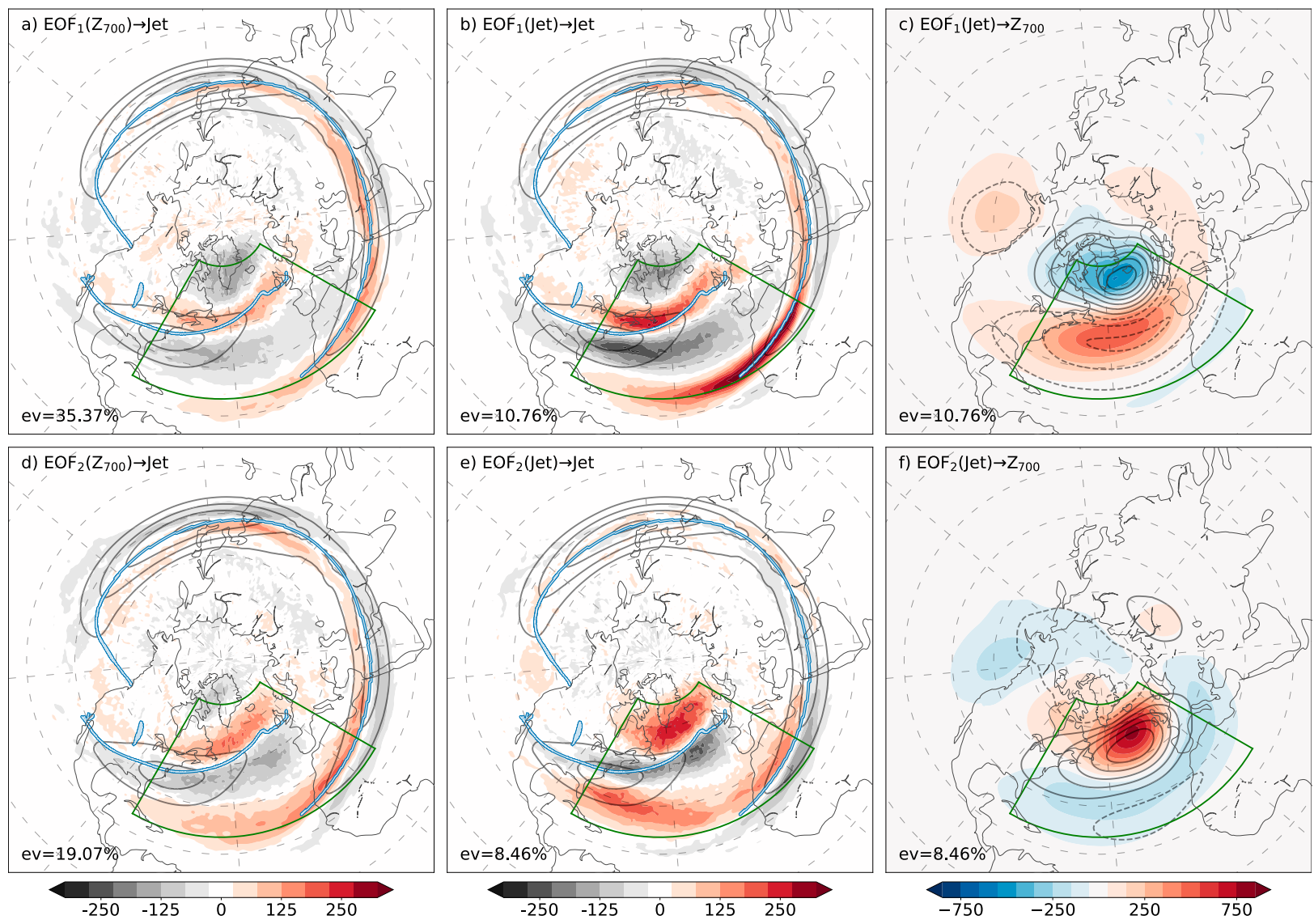

FIG. 5. Regressed jet axis distributions [average line length; $\mathrm{km}(1000 \mathrm{~km})^{-2}$ ] based on (a),(b) EOF1 and (d),(e) EOF2 of (left) 700-hPa geopotential and (center) the monthly jet axis distribution in the North Atlantic domain marked in green. All EOFs are for boreal winter. The geopotential-based EOFs in (a) and (d) correspond to the NAO and the EA, respectively. Black contours show the winter mean wind speed with an interval of $10 \mathrm{~m} \mathrm{~s}^{-1}$ starting at $30 \mathrm{~m} \mathrm{~s}^{-1}$, and the blue-white lines connect maxima in the seasonal jet axis distribution. (c),(f) 700-hPa geopotential $\left(\mathrm{m}^{2} \mathrm{~s}^{-2}\right)$ regressed onto the jet axis-based EOFs (shading) of (b) and (e), respectively, and the corresponding geopotential-based EOFs (contours; contour interval of $200 \mathrm{~m}$; the outermost contours represent the \pm 100 -m isohypses). The label "ev" indicates the respective explained variance of the underlying EOF.

jet axis distribution" $\left[l_{i} / A\right.$ in the nomenclature of Eq. (1)], we refer to the resulting $\chi_{\text {reg }}$ as the "regressed jet axis distribution." For simplicity, we will in the following refer to $\chi_{\text {reg }}$ as the "EOF pattern of variable $\chi$ " if $\chi=\psi$ (i.e., if referring to a regression of a variable onto its own EOF pattern).

\section{a. North Atlantic}

\section{1) WINTER VARIABILITY}

The two dominant modes of geopotential and sea level pressure variability for the boreal winter (DJF) represent the NAO and the EA (Wallace and Gutzler 1981), respectively. Both the geopotential and the jetbased patterns leave a clear imprint on the regressed jet axis distribution over the North Atlantic as well as on the subtropical jet from Africa to Asia (Figs. 5a,b,d,e).
The first EOFs are characterized by either a comparatively zonal and merged eddy-driven and subtropical jet (cf. $\mathrm{NAO}^{-}$) or a regime with a northward displaced eddydriven jet and a separate subtropical jet $\left(\mathrm{cf} . \mathrm{NAO}^{+}\right)$ (Fig. 5a). Our patterns are thus consistent with the widely recognized interpretation of the NAO as a latitudinal shift of the North Atlantic jet (cf. Fig. 1a). In addition, they also suggest that the NAO constitutes a covariability of the eddy-driven and subtropical jet. For our EOFs, this covariability of the subtropical jet leads to a latitudinal shifting of the subtropical jet over the Asian continent and west Pacific.

The imprint of our second EOF on the jet is structurally very similar to that of the first, but latitudinally shifted by about half the meridional extent of the anomalies such that the patterns are nearly in quadrature (cf. Figs. 5a,d). The tripole pattern in the jet axis distribution over the U.S. East Coast indicates that the 
EA represents a pulsing-type variability in this region (Fig. 5d). As Fig. 1b illustrates, a variation between a stronger jet occurring in a spatially confined area, and a weaker meandering jet yields a tripolar pattern in the jet axis distribution. In the east Atlantic, however, the climatological mean jet position (blue-white line) is located in the center between two anomaly lobes of opposite sign, indicating predominantly latitudinal shifting around the climatological jet position (Fig. 5e). The reduced frequency of jet detections to the south of the climatological jet position is consistent with the pronounced anticyclonic anomaly over the British Isles (cf. $\mathrm{EA}^{-}$) documented by Wallace and Gutzler (1981). Similar to our first EOF, our second EOF represents a covariabilty of the eddy-driven and subtropical jet. In the geopotential-based EOF, the subtropical jet consistently shifts from West Africa throughout most of the Pacific sector (Fig. 5d) and thus bears some resemblance to the first hemispheric EOF in Strong and Magnusdottir (2008).

The intrinsic jet variability in the North Atlantic is consistent with the canonical NAO and EA patterns and indexes (Figs. 5b,e; Table 1). Naturally, the regressions based on the jet axis-based EOFs lead to stronger anomalies than those based on the geopotential-based EOFs, but the spatial configuration and extent of the anomalies is nearly identical. The main difference is the anomaly over Asia, which is somewhat more diffuse in the jet axis-based EOFs, in particular for the one corresponding to the EA (Fig. 5e). The regressions of the jet axis-based EOFs onto geopotential recover the canonical NAO and EA patterns (Figs. 5c,f). Overall, the geopotential-variability-based patterns in the North Atlantic thus capture the intrinsic variability of the jet well.

The correspondence of the NAO and the EA to either a latitudinal shifting or pulsing-type variability is, however, less straightforward. The EA describes a changeover from predominantly pulsing over the U.S. East Coast toward latitudinal shifting over the east Atlantic. Conversely, the NAO represents a clear latitudinal shift of the jet over the U.S. East Coast, but toward Europe the pattern becomes more tripolar, indicating that a northward displaced jet over the U.S. East Coast corresponds to a less meandering and hence more intense jet over Europe $\left(\mathrm{NAO}^{+}\right)$and vice versa.

Our results are largely consistent with Athanasiadis et al. (2010) and Wettstein and Wallace (2010), who considered the intrinsic variability of the upper-level zonal wind and meridional wind variance, as well as the variance of midtropospheric geopotential. In all their EOFs, the two dominant patterns clearly correspond to the NAO and the EA, respectively, and the association of the obtained variability patterns with either shifting or pulsing jet variability is rather straightforward. However, each variable yields a different type of variability for either the NAO or EA. Thus, their results do not allow unequivocal characterization of the NAO or EA as either a shifting or pulsing type of storm-track variability. This ambiguity in pulsing and shifting is in line with the results of Woollings et al. (2010), who documented that both the NAO and the EA represent a concomitant variability in the intensity and the location of the maximum low-level winds in the North Atlantic. It thus seems impossible to uniquely associate either the NAO or the EA with one of these conceptually well-founded archetypes of storm track variability.

\section{2) SUMMER VARIABILITY}

The correspondence between geopotential and jet variability applies also to summer variability in the North Atlantic (Fig. 6). The first EOF again represents the NAO, and the second the EA. The spatial patterns of these patterns, however, differ between summer and winter. Not only are the amplitudes of the anomalies, in particular for geopotential, considerably smaller in summer compared to winter, but also the locations of the anomalies differ. For example, the positive anomaly of the NAO pattern is located at $45^{\circ} \mathrm{W}$ during summer, but at around $20^{\circ} \mathrm{W}$ in winter (Figs. $5 \mathrm{c}$ and $6 \mathrm{c}$ ). Further, in summer the positive geopotential anomaly in the NAO pattern is part of a circumpolar, though not particularly annular, band of positive anomalies.

In addition, the association of the NAO and the EA with shifting and pulsing-type variability appears different during summer than during winter. In the NAOlike EOF1, the climatological mean jet axis marks the center of a tripolar pattern, indicating pulsing associated with the NAO during summer. Conversely, for the EA the climatological mean axis appears centered between the lobes of a dipole, suggesting an association of the EA with latitudinal shifting during summer.

\section{b. North Pacific}

\section{1) WINTER VARIABILITY}

The canonical variability patterns over the North Pacific are the Pacific-North America pattern and the west Pacific pattern (Wallace and Gutzler 1981). The order in which these patterns appear in an EOF analysis depends on the variable or diagnostic in question (Lau 1988; Athanasiadis et al. 2010; Wettstein and Wallace 2010) as well as on the exact definition of the considered season (not shown). To be consistent with our seasonal climatologies as well as the analyses for 

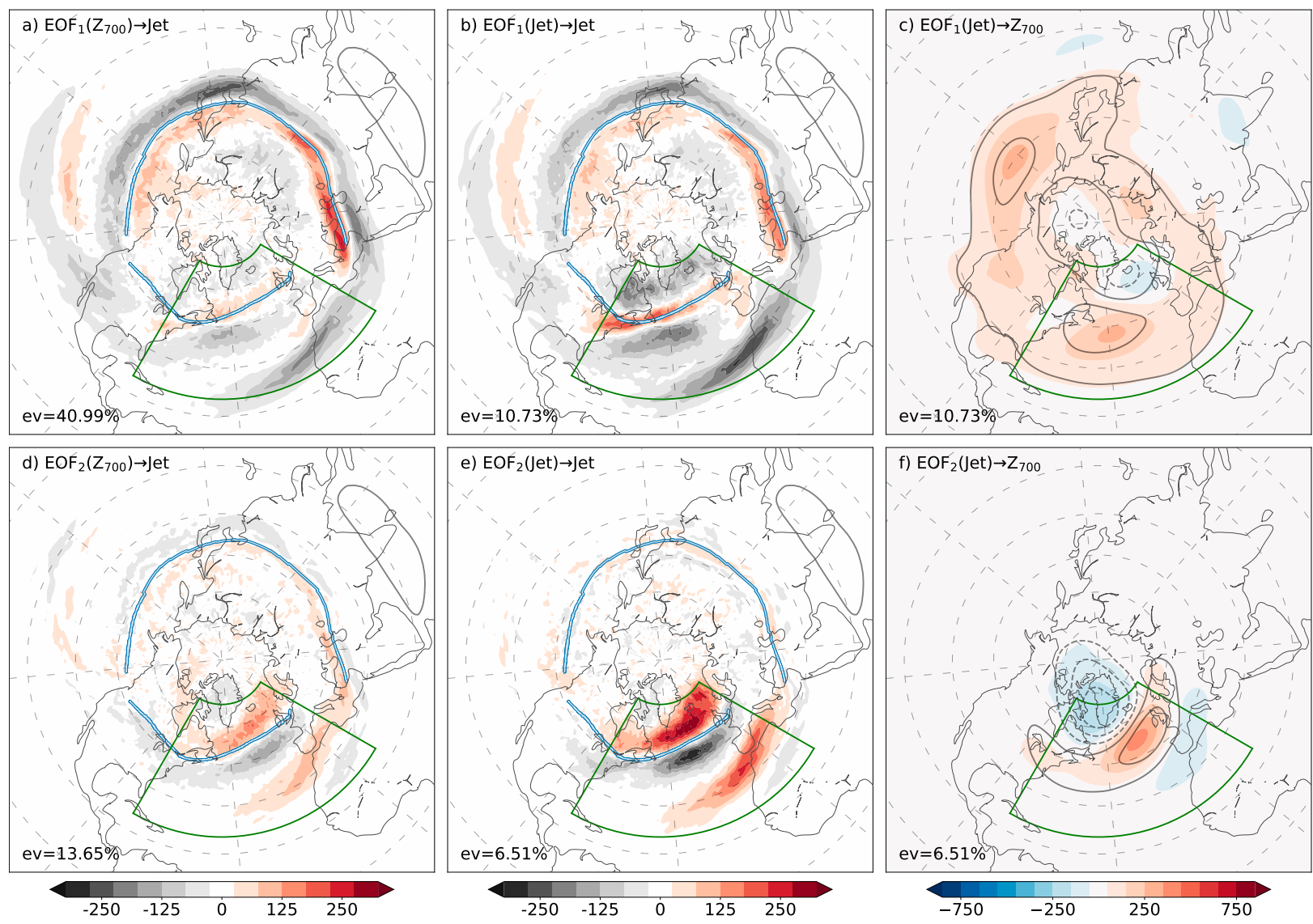

FIG. 6. As in Fig. 5, but for the summer.

the other ocean basins, we first diagnose the boreal winter variability (DJF).

For this definition of winter, the dominant pattern for both geopotential and jet axis variability corresponds to the WP (Figs. 7a-c). Analogously to the North Atlantic, the first pattern in the North Pacific describes a latitudinal shift of the jet in the western part of the ocean basin, and a pulsing-type tripole or double-jet structure in the eastern part of the ocean basin (Figs. 7a,b). In addition, the regression of geopotential onto the jet axis-based EOF is structurally similar to the NAO with a negative anomaly at subpolar latitudes accompanied by a positive anomaly in the midlatitudes. The existence of NAO-like variability in the North Pacific was already suggested by Walker and Bliss (1932) and is consistent with Wallace and Gutzler (1981), associating this NAOlike variability with the WP. The regression of our jet axis-based EOF onto geopotential is consistent with the canonical WP (see Table 1), but the pattern is shifted by approximately $20^{\circ}-30^{\circ}$ eastward toward the central Pacific (Fig. 7c).
The second EOFs of both the geopotential and the jet axis distribution correspond to the PNA (Figs. 7d-f). The regression of geopotential onto the jet axis-based EOF is consistent with the variability of geopotential itself, even though the subtropical anticyclonic anomaly is less pronounced in the jet axis-based pattern (Fig. 7f). From a jet axis perspective, both of our EOFs feature a tripole pattern throughout the Pacific (Figs. 7d,e), suggesting a comparatively clear-cut association of these patterns with a pulsing-type variability (Eichelberger and Hartmann 2007; Woollings et al. 2018) influenced by tropical heating ( $\mathrm{Li}$ and Wettstein 2012). It is thus not surprising that the PNA has been shown to be modulated by both ENSO (e.g., Renwick and Wallace 1996) and the MJO (e.g., Moore et al. 2010). Note, however, that the climatological jet axis is not centered on the central lobe of the tripole, suggesting a slight component of latitudinal shifting associated with our patterns in addition to the pulsing (Figs. 7d,e).

Considering the total jet axis distributions (not shown), our second EOFs represent variations in how 

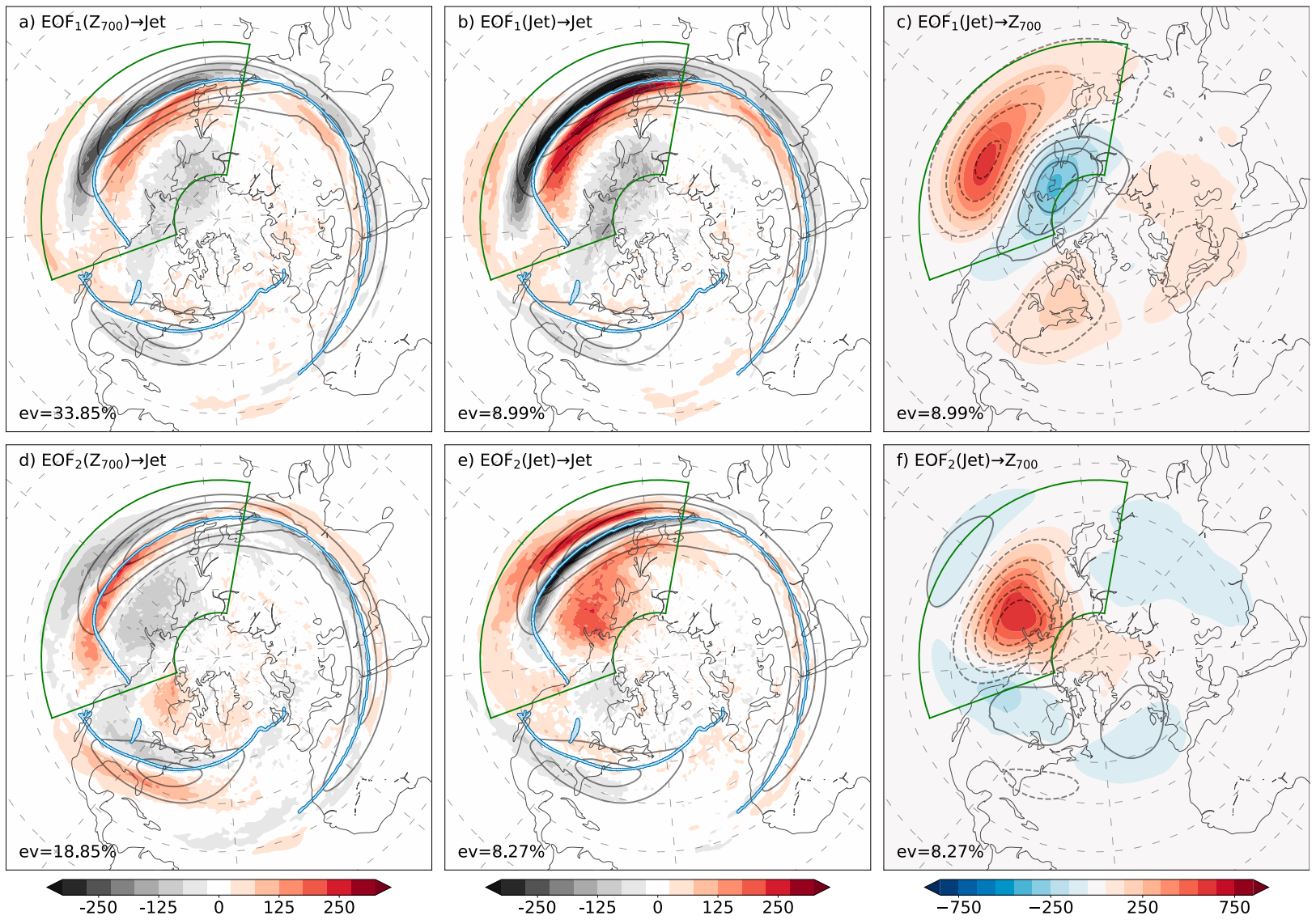

FIG. 7. As in Fig. 5, but for the North Pacific, where the two dominant EOFs correspond to the WP and the PNA, respectively.

far east the coherent and strong united eddy-driven and subtropical jet extends across the North Pacific. During the negative phase (cf. $\mathrm{PNA}^{-}$), the jet axis distribution becomes markedly broader eastward of the the date line, indicating a meandering jet in the eastern Pacific. In contrast, during their positive phase $\left(\mathrm{cf} . \mathrm{PNA}^{+}\right)$the jet distribution is focused on the climatological mean jet position for most of the east Pacific.

Our results feature only minor deviations in the location and strength of the anomaly lobes compared to the canonical PNA and WP patterns. Further, our results are in line with the documented variability of the upper-level zonal wind, upper-level meridional wind variance, and midtropospheric geopotential variance (Athanasiadis et al. 2010; Wettstein and Wallace 2010). Correlations between our and the canonical indexes are between 0.61 and 0.77 (Table 1).

A complicating factor for any study of North Pacific winter variability is the midwinter suppression of storm track activity (Nakamura 1992; Afargan and Kaspi 2017). This suppression is most pronounced during January and February, suggesting that the exact definition of the winter season can have a considerable impact on the dominant variability patterns. Using DJF, we largely characterize variability of the suppressed storm track, whereas analyses based on extended winter seasons [December-March in Athanasiadis et al. (2010); November-March in Lau (1988) and Wettstein and Wallace (2010)] inevitably include more of the storm track transitions in and out of the suppressed state in their patterns.

\section{2) SUMMER VARIABILITY}

In the Pacific, only the first EOF remains consistent between summer and winter (Fig. 8). As in winter, the first EOF marks a latitudinal shift of the jet over large parts of the North Pacific and the Asian continent (Figs. 8a-c). For the second EOF, however, geopotential and jet axes represent different variability patterns (Figs. 8d-f). Whereas the regression of the geopotentialbased EOF2 is also associated with a latitudinal shift of the jet (Fig. 8d), the jet-based EOF2 represents the appearance or disappearance of a subtropical jet over the eastern North Pacific (Fig. 8e). 

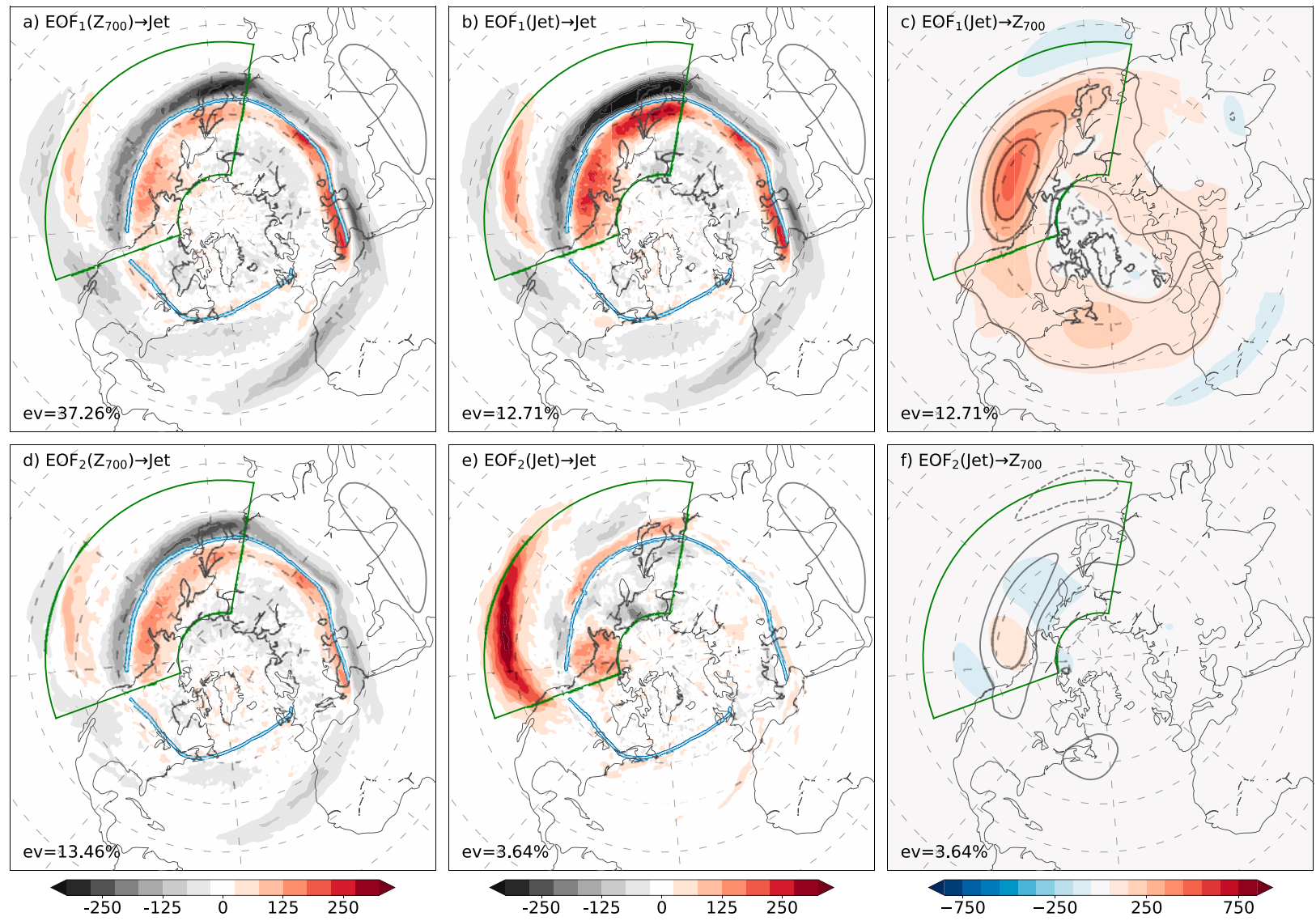

FIG. 8. As in Fig. 5, but for the North Pacific and summer.

\section{c. South Atlantic}

\section{1) WINTER VARIABILITY}

The South Atlantic is characterized by a rather broad band $\left(30^{\circ}-50^{\circ} \mathrm{S}\right)$ of moderate wind speeds without a well-defined climatological maximum, which is most likely associated with both the subtropical and eddydriven jet being frequently present in this ocean basin (Figs. 4 and 9a,b). However, it is not straightforward to disentangle these two jet types in this region, because a new storm track emerges in the lee of the Andes at comparatively low latitudes [see low-latitude cyclone detections for many schemes in Neu et al. (2013)] and cyclogenesis spreading from the subtropics to Drake Passage along the South American east coast (Reboita et al. 2010). This broad latitudinal spread of cyclogenesis is consistent with the climatologically broad range of moderately strong wind speeds between about $30^{\circ}$ and $50^{\circ} \mathrm{S}$ and a vacillation between a one-jet and a two-jet state in the South Atlantic.
The leading EOFs of geopotential and jet axis distribution do not bear any strong similarities (cf. Fig. 9a with Fig. 9b, and Fig. 9d with Fig. 9e). While the jet axisbased EOFs have a comparatively zonally symmetric structure (Figs. 9b,e), the regression of the jet axis distribution onto the geopotential-based EOFs features pronounced zonal asymmetries (Figs. 9a,d). Conversely, the regression of geopotential onto the jet axis-based EOFs yields rather weak anomalies that do not correspond to the intrinsic geopotential variability (Figs. 9c,f).

The discrepancy between the geopotential and jet axis-based perspectives on South Atlantic variability indicates either that the chosen variables are not the most pertinent for this region or that the boundaries of the region are chosen such that they do not capture the dominant physical processes. Given the conceptual and physical importance of the selected storm track metrics, the choice of the metrics is an implausible explanation for the discrepancy. Regarding the choice of the region, Spensberger et al. (2020) reported analogous results for an annular domain covering the southern midlatitudes, 

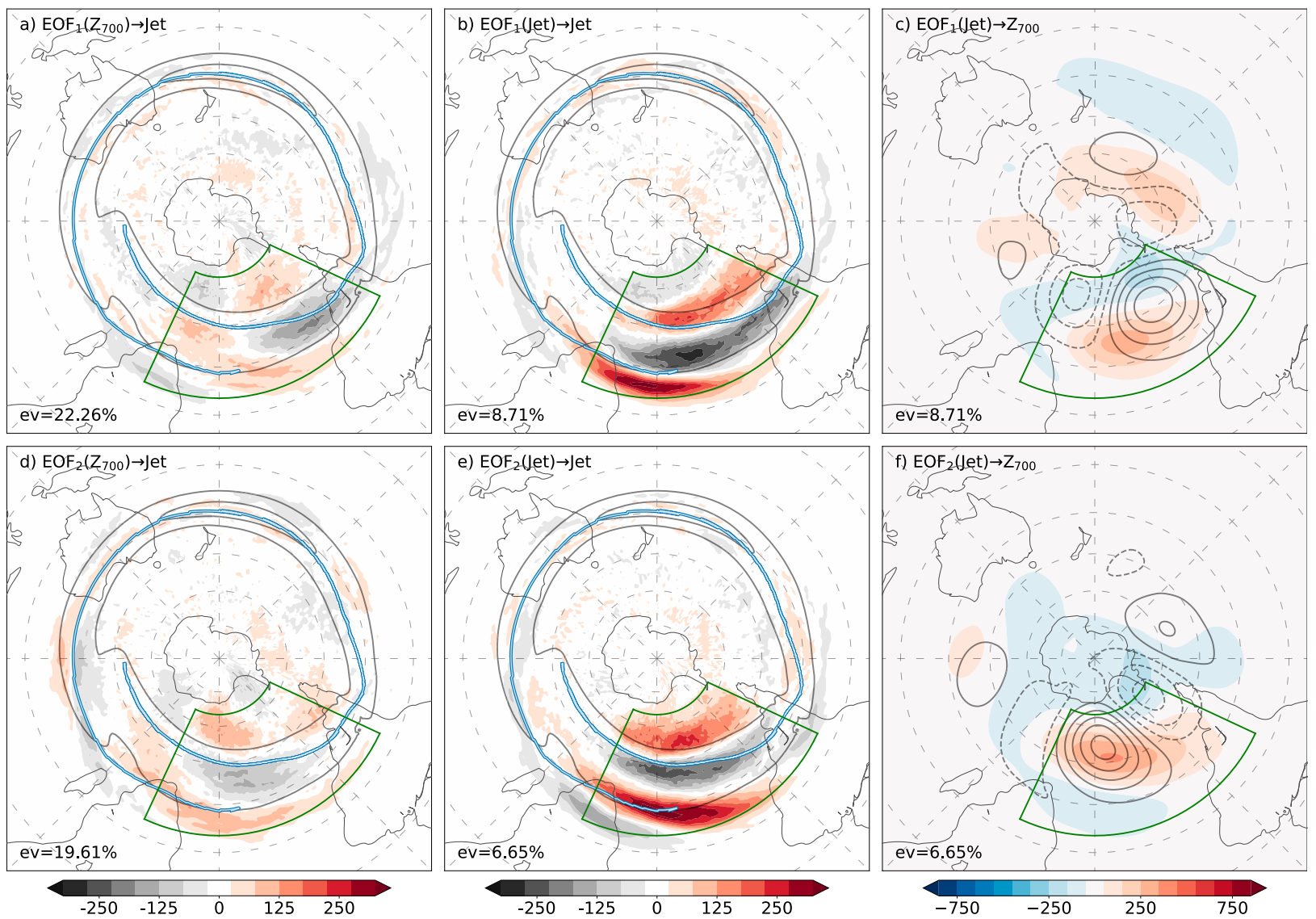

FIG. 9. As in Fig. 5, but for the South Atlantic and austral winter.

which also renders the choice of the region an unlikely explanation for the discrepancy.

Consequently, the most likely reason for the discrepancy is the choice of the method. Although an EOF analysis successfully identifies variability patterns in the Northern Hemisphere, EOFs may not inevitably yield physically meaningful variability patterns for all ocean sectors, irrespective of the chosen variable. Alternative approaches such as cluster analysis as well as indices based directly on physical processes might prove to be more insightful for this region. For example, the documented preferred latitudes of cyclogenesis along the South American east coast (Reboita et al. 2010) might provide the basis for a regime index analogous to the Woollings et al. (2010) North Atlantic jet latitude index. Alternatively, a more thorough classification into weather regimes could be used to identify consistent variability patterns (e.g., Grams et al. 2017).

\section{2) SUMMER VARIABILITY}

In contrast to winter, the respective first EOFs of geopotential and jet variability during summer point to the same kind of variability (Figs. 10a-c). In geopotential, this variability is expressed as a dipole with one anomaly lobe covering most of Antarctica and the other lobe in the South Atlantic midlatitudes (Fig. 10c). The midlatitude anomaly goes along with hints of an annular structure in the midlatitudes, made up by some traces of similar anomalies in the south Indian Ocean and the South Pacific. From a jet perspective, this pattern mostly represents a latitudinal shift of the eddy-driven jet in the South Atlantic (Figs. 10a,b), as the climatological jet position is generally centered between two anomaly lobes. The shifting pattern is clearly concentrated in the South Atlantic, but extends also well into the south Indian Ocean when the EOF is based on geopotential (Fig. 10a).

The respective second EOFs of the jet axis distribution and geopotential again point to different kinds of variability (Figs. 10d-f). From a jet perspective, the second EOF represents a latitudinal shift in the eastern half of the domain that is associated with a dipole in geopotential (Fig. 10e, shading in Fig. 10f). In contrast, the second EOF of geopotential is a monopole (contours in Fig. 10f), associated with a tripole in the jet axis distribution (Fig. 10d). 

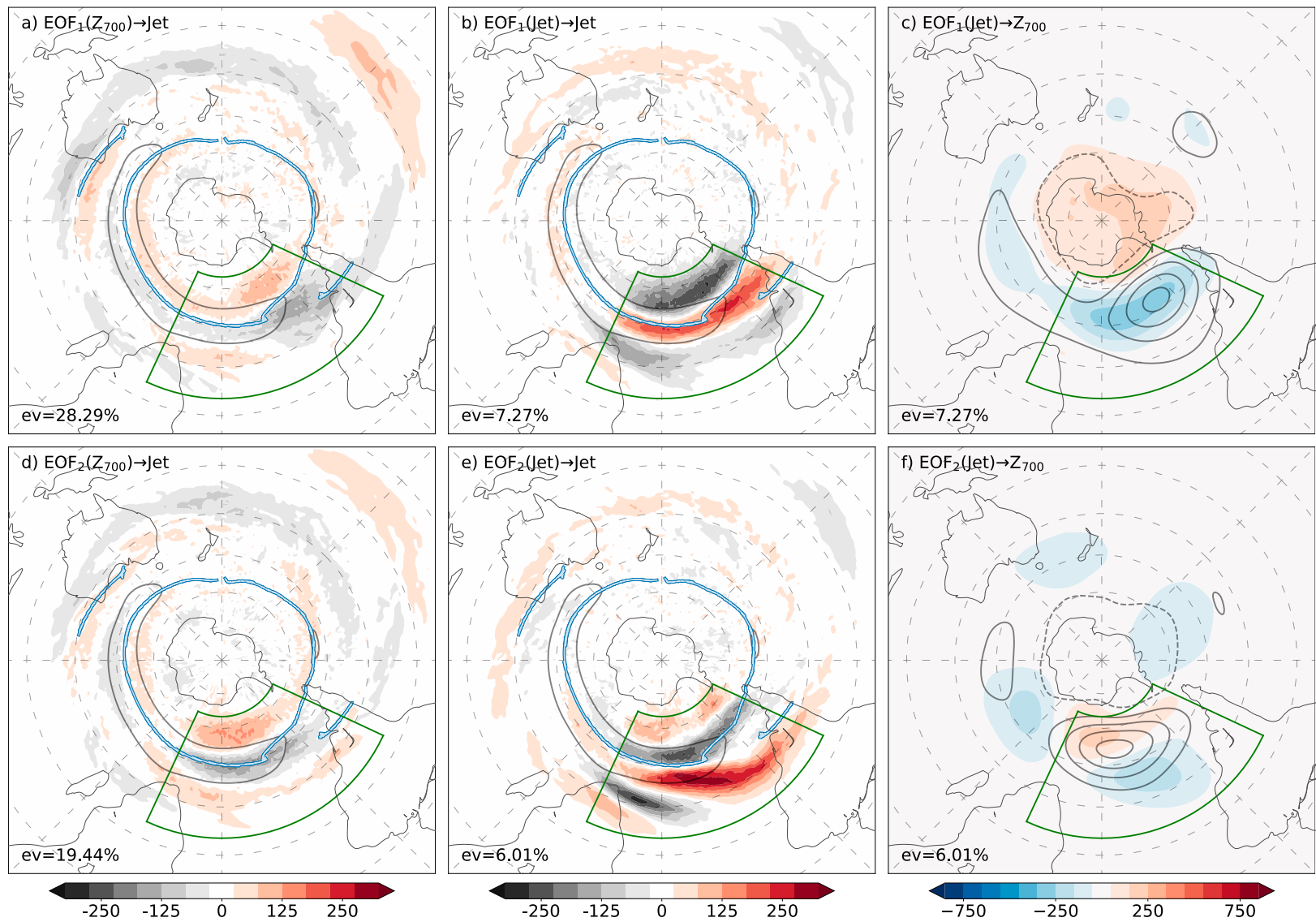

FIG. 10. As in Fig. 5, but for the South Atlantic and austral summer.

\section{d. South Indian Ocean}

\section{1) WINTER VARIABILITY}

Both leading jet-based EOFs in the south Indian Ocean represent a latitudinal shift of the subtropical jet (Figs. 11b,e), where an equatorward shift of the subtropical jet is associated with the appearance of a separate eddy-driven jet in EOF1 (Fig. 11b) and with with an equatorward shift of the eddy-driven jet in EOF2 (Fig. 11e). The latitudinal shift of the subtropical jet is associated with weak geopotential anomalies (Figs. 11c,f). For EOF1, a pronounced anticyclonic anomaly in the midlatitudes extends far enough equatorward to slightly decrease the geopotential gradient on the poleward side of the climatological subtropical jet position (Fig. 11c). For EOF2, a slightly weakened subtropical anticyclone is associated with a poleward shift of the subtropical jet, while a more pronounced midlatitude anticyclone displaces the eddy-driven jet (Fig. 11f).

The respective leading patterns of geopotential and jet axis variability yield consistent projections on geopotential and the jet axis distribution (Figs. 11a-c). The correspondence between jet axis and geopotential variability for EOF1 makes the pattern a candidate to further investigate the physical mechanisms driving variability in the south Indian Ocean sector (Spensberger et al. 2020). A similar latitudinally shifting variability was also found by Ogawa et al. (2016), although their pattern features stronger zonal asymmetries.

\section{2) SUMMER VARIABILITY}

The first EOFs representing south Indian Ocean summer variability are consistent with each other (Figs. 12a-c) and structurally similar to the respective patterns for the South Atlantic (Figs. 10a-c). As in the South Atlantic, the pattern represents a latitudinal shift of the eddy-driven jet (Figs. 12a,b) and a dipole in geopotential between the Antarctic continent and the midlatitudes (Fig. 12c). As in the South Atlantic, there are traces of an annular structure in the midlatitude geopotential anomalies. However, in contrast to the South Atlantic, the eddy-driven jet in the south Indian Ocean is hardly correlated with other ocean sectors.

These findings are partly in line with the discussion of winter SAM in Spensberger et al. (2020). As during winter, these patterns in the South Atlantic and south 

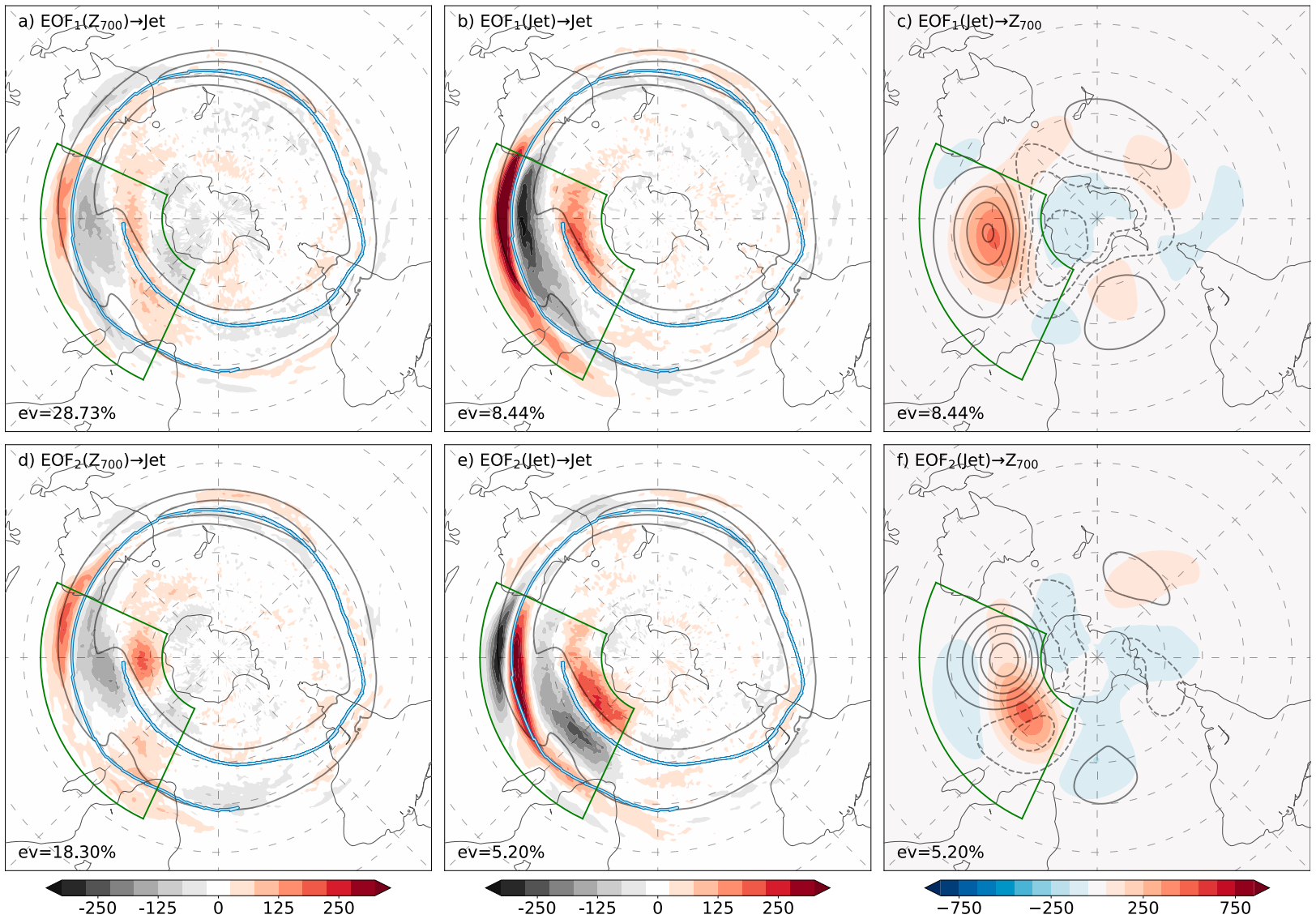

FIG. 11. As in Fig. 5, but for the south Indian Ocean and austral winter.

Indian Ocean exhibit stronger hemispheric correlations for geopotential than for the jet axis distribution, and for geopotential over Antarctica than geopotential in the midlatitudes. These parallels suggest that the Spensberger et al. (2020) interpretation of winter SAM might at least partly apply also during summer. They interpreted SAM as predominantly capturing sea level pressure and temperature variations along the Antarctic coastline and over the Antarctic continent.

Nevertheless, there are important differences between winter SAM and the summer patterns discussed here. First and foremost, during winter Spensberger et al. (2020) found hardly any correlation between SAM and the jet axis distribution, whereas the first summer EOFs in the South Atlantic and south Indian Ocean both exhibit a covariability of the jet and the geopotential. Further, during winter, the hemispheric correlations in geopotential vanish when Antarctica is excluded from the EOF domain (Spensberger et al. $2020)$. We use the same cutoff latitude $\left(65^{\circ} \mathrm{S}\right)$ here as in Spensberger et al. (2020), but nevertheless uncover large-scale geopotential variations over Antarctica during summer. These differences suggest that, in contrast to winter, there might be a relation between SAM and the Southern Hemisphere summer storm track.

The respective second EOFs of summer variability in the south Indian Ocean again point to different kinds of variability. The second jet-based EOF is the only jetbased EOF in this study with marked zonal asymmetries across the domain. The pattern is associated with a clear wave train in geopotential, although the jet axis distribution fits neither the latitudinal shifting nor the pulsing archetypes and is thus difficult to interpret. In contrast, the geopotential-based second EOF constitutes a weak dipole in geopotential associated with a pulsing tripole centered on the eddy-driven jet.

\section{e. South Pacific}

\section{1) WINTER VARIABILITY}

As documented by Spensberger et al. (2020), the closest correspondence between geopotential and jet axis-based variability in the Southern Hemisphere is for the leading EOFs in the Pacific sector. Analogously to 

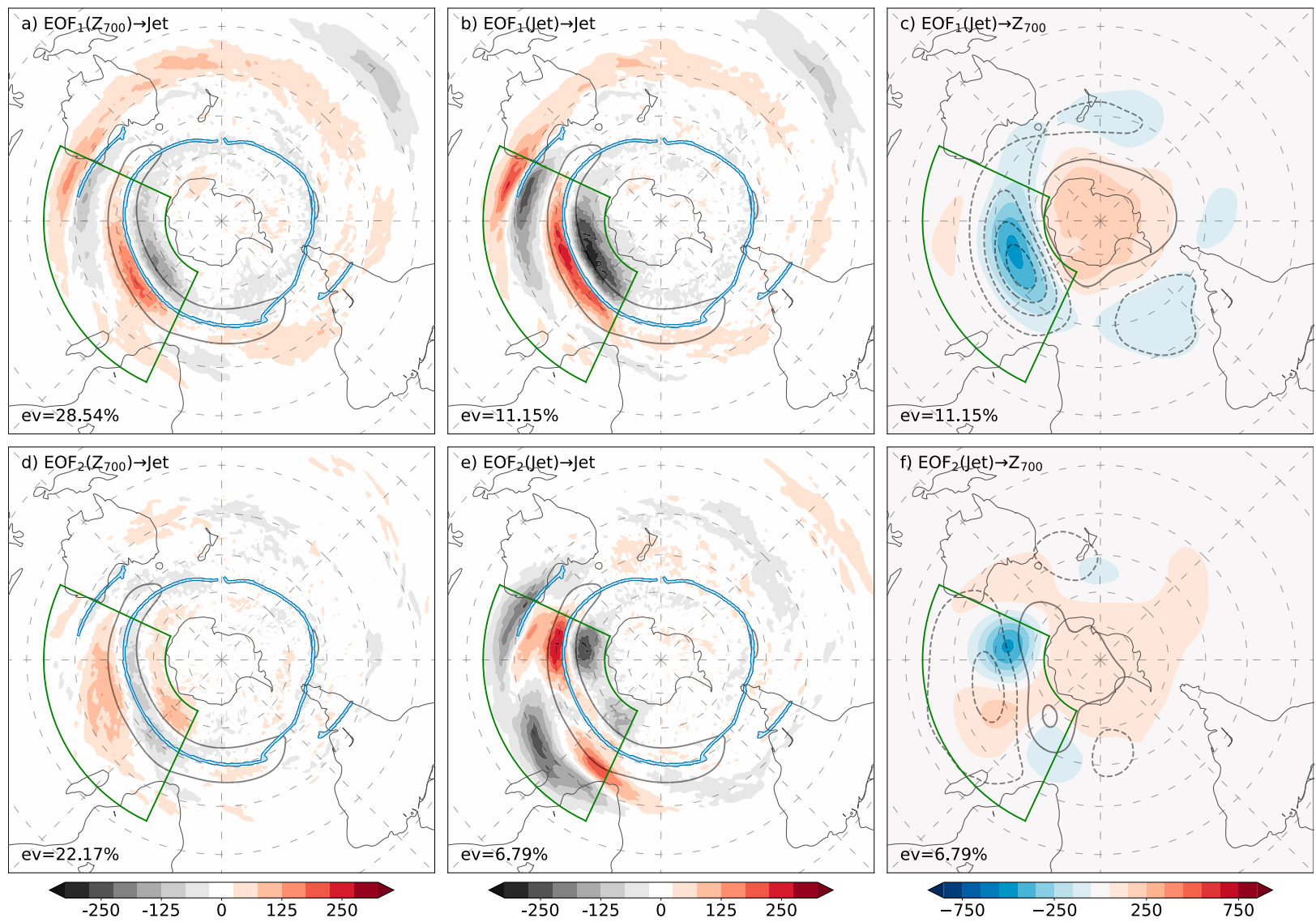

FIG. 12. As in Fig. 5, but for the south Indian Ocean and austral summer.

the NAO and the WP (Figs. 5a-c and 7a-c), the leading EOF represents predominantly a latitudinal shifting in the western part of the ocean basin, which gradually changes character toward predominantly pulsing in the eastern part (Figs. 13a-c). Both the leading EOFs in the South Pacific and the NAO are associated with a pronounced dipole in geopotential (Figs. 5c and 13c). Comparing the jet axis and geopotential-based variability in the South Pacific, the jet axis-based EOF emphasizes variability toward the end of the storm track, but the overall structure is very consistent (Figs. 13a-c).

Spensberger et al. (2020) show that the time series of this leading pattern of South Pacific variability is highly correlated with the first mode of the PacificSouth America pattern (PSA) (Lau et al. 1994; O'Kane et al. 2017). However, in contrast to the NAO, Lau et al. (1994) interpret the two modes of the PSA as a moving wave train in the South Pacific. This interpretation is inconsistent with our results, as we do not find an equivalent to PSA2 in the South Pacific based on jet axis variability, even though our EOF domain encompasses the wave trains documented by Lau et al. (1994).
For the respective second EOFs in the Pacific sector, the geopotential and jet axes again yield different patterns of variability (Figs. 13d-f). The correspondence of the regressions is weak and the jet axis-based and geopotential-based EOFs project on different structures in the jet axis distribution (Figs. 13d-f). The jet axisbased EOF2 yields a latitudinally shifting pattern of the subtropical jet throughout the South Pacific. When shifted equatorward, the subtropical jet is more frequently accompanied by a separate eddy-driven jet between $45^{\circ}$ and $60^{\circ} \mathrm{S}$. In contrast, the imprint of the geopotential-based EOF2 on the subtropical jet is zonally asymmetric (Fig. 13d), associated with the wave train in geopotential (Fig. 13f), with no coherent signal associated with the eddy-driven jet. Despite the wave trainlike appearance of the geopotential-based EOF2 (contours in Fig. 13f), Spensberger et al. (2020) documented a weak correlation (0.42) of the corresponding index time series with PSA2.

\section{2) SUMMER VARIABILITY}

For the South Pacific summer (Fig. 14), we do not find an equivalent to the SAM-like patterns we observed for 

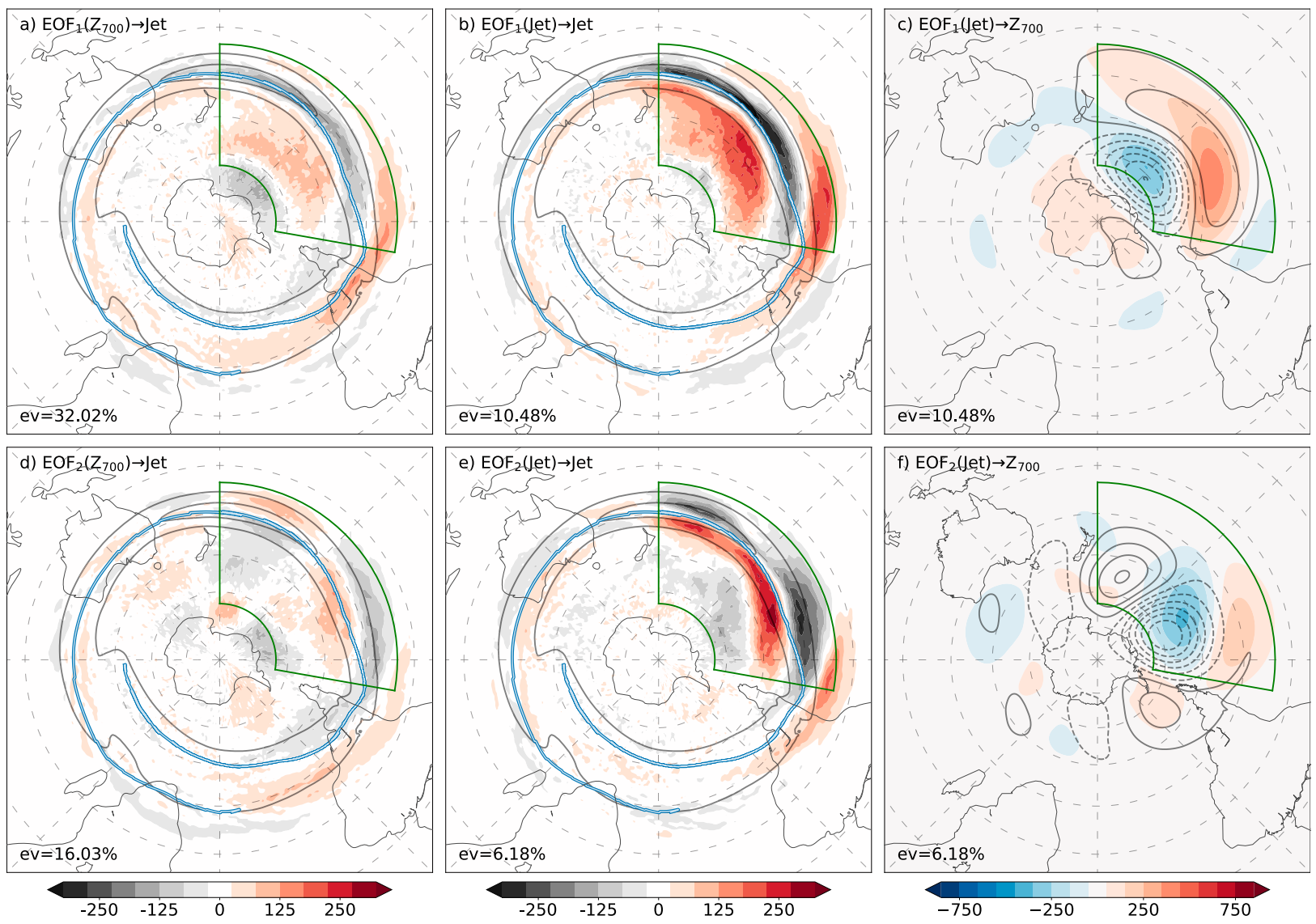

FIG. 13. As in Fig. 5, but for the South Pacific and austral winter, where Spensberger et al. (2020) reported a correlation of 0.69 between EOF1 and the first mode of the Pacific-South America pattern (PSA1).

the South Atlantic and the south Indian Ocean. Indeed, for neither of the leading two EOFs do we find a correspondence between geopotential and the jet axis distribution. This difference between the South Pacific and the other ocean sectors in the Southern Hemisphere challenges our interpretation of the South Atlantic and south Indian Ocean patterns as representing some aspect of SAM during summer. Either the relation between our patterns in these sectors and summer SAM is weak, or the name "annular mode" is misleading in that the mode of variability primarily arises from two ocean sectors rather than the entire hemisphere.

\section{Influence of tropical variability}

Tropical variability has been shown to significantly impact storm tracks (e.g., Moore et al. 2010; Li and Wettstein 2012; Schemm et al. 2016, 2018). We therefore discuss the impact of El Niño-Southern Oscillation (ENSO) and the Madden-Julian oscillation (MJO) on the jet axes and storm tracks in both hemispheres. We base our analyses on the second version of the multivariate ENSO index (MEI.v2) of Zhang et al. (2019), and the Wheeler and Hendon (2004) MJO index.

\section{a. Correlation with ENSO}

In both hemispheres, ENSO leaves a clear imprint on the jet axis distribution during boreal winter (Figs. 15a,b). The most pronounced anomalies occur in the Northern Hemisphere, constituting an equatorward shift of the subtropical jet from East Africa throughout Asia and into the western Pacific during $\mathrm{ENSO}^{-}$. This latitudinal shift is associated with a comparatively weaker and more diffuse tripole pattern over the eastern North Pacific (Fig. 15a), similar to the pulsing tripole observed for the PNA (Figs. 7d,e). The ENSO-related tripole is, however, located farther eastward than the one related to the PNA. Nevertheless, the similarity is consistent with the results of Renwick and Wallace (1996), who documented a covariability of ENSO and the PNA together with a tendency for more frequent blocking in the eastern North Pacific during $\mathrm{ENSO}^{-}$. 

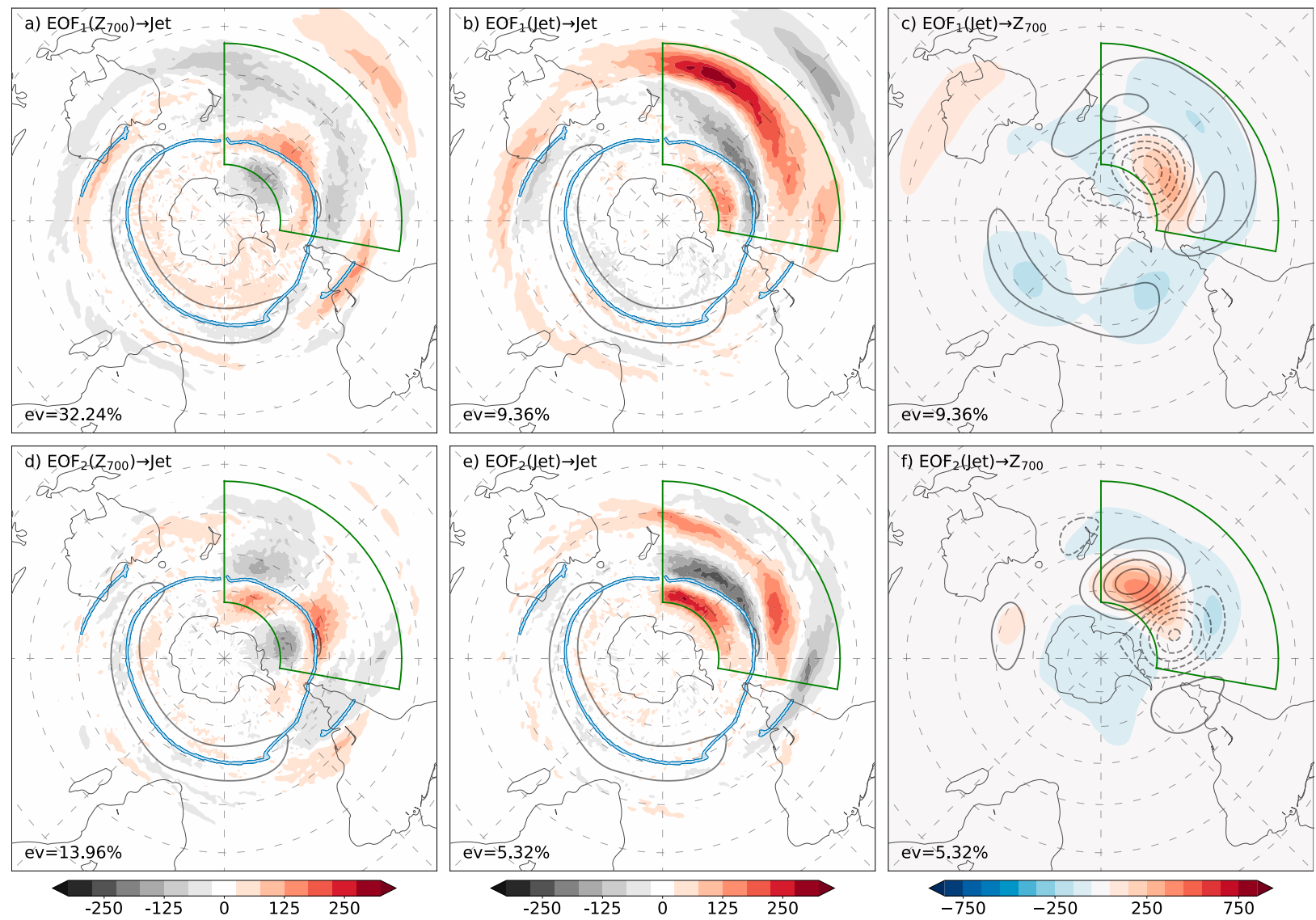

FIG. 14. As in Fig. 5, but for the South Pacific and austral summer.

In the Southern Hemisphere, the strongest signal during boreal winter appears in the tropical South Pacific centered around $10^{\circ} \mathrm{S}$ (Fig. 15b). This signal is associated with the regular occurrence of westerlies throughout the tropics, which is referred to as the westerly duct as it allows the propagation of Rossby waves across the equator (Webster and Holton 1982; Hoskins and Ambrizzi 1993). Consistently with Manney et al. (2014) and Manney and Hegglin (2018), the strongly negative anomaly associated with $\mathrm{ENSO}^{+}$ (Fig. 15b) suggests that the westerly duct preferentially occurs during phases of La Niña $\left(\mathrm{ENSO}^{-}\right)$. This relation is consistent with the finding of Waugh and Polvani (2000), who document a reduced frequency of intrusions of midlatitude air toward the westerly duct during $\mathrm{ENSO}^{+}$, suggesting that El Niño events reduce, or potentially even block, the interhemispheric communication through the westerly duct.

During austral winter, ENSO mainly affects the Southern Hemisphere jet axis distribution (Fig. 15d) and the signal in the Northern Hemisphere is weak and incoherent (Fig. 15c). The effect on the Southern Hemisphere is mostly analogous to the effect on the
Northern Hemisphere boreal winter jet axis distribution (Fig. 15a), although more diffuse. Starting in the Atlantic, throughout the Indian Ocean, up to the western South Pacific, the subtropical jet shifts equatorward during $\mathrm{ENSO}^{+}$(Fig. 15d). This latitudinal shift is associated with a pulsing tripole in the eastern Pacific with a more focused single jet during $\mathrm{ENSO}^{+}$(Fig. 15d). The full jet axis distribution indicates a tendency for a double-jet structure in the eastern South Pacific during $\mathrm{ENSO}^{-}$(not shown).

\section{b. Correlation with the $\mathrm{MJO}$}

The response of the jet distribution to the MJO is broadly similar to that of ENSO (Figs. 15 and 16). As for ENSO, the response in the Northern Hemisphere is largely limited to boreal winter (Figs. 16a,c). Over East Africa and the Asian continent, the jet predominantly shifts poleward with an active $\mathrm{MJO}$ in the region (Fig. 16a). Over the North Pacific, the jet predominantly displays a pulsing-type variability with a stronger more focused jet and amplified tropical convection over the central Pacific during MJO phase 7 compared to phase 3 . 

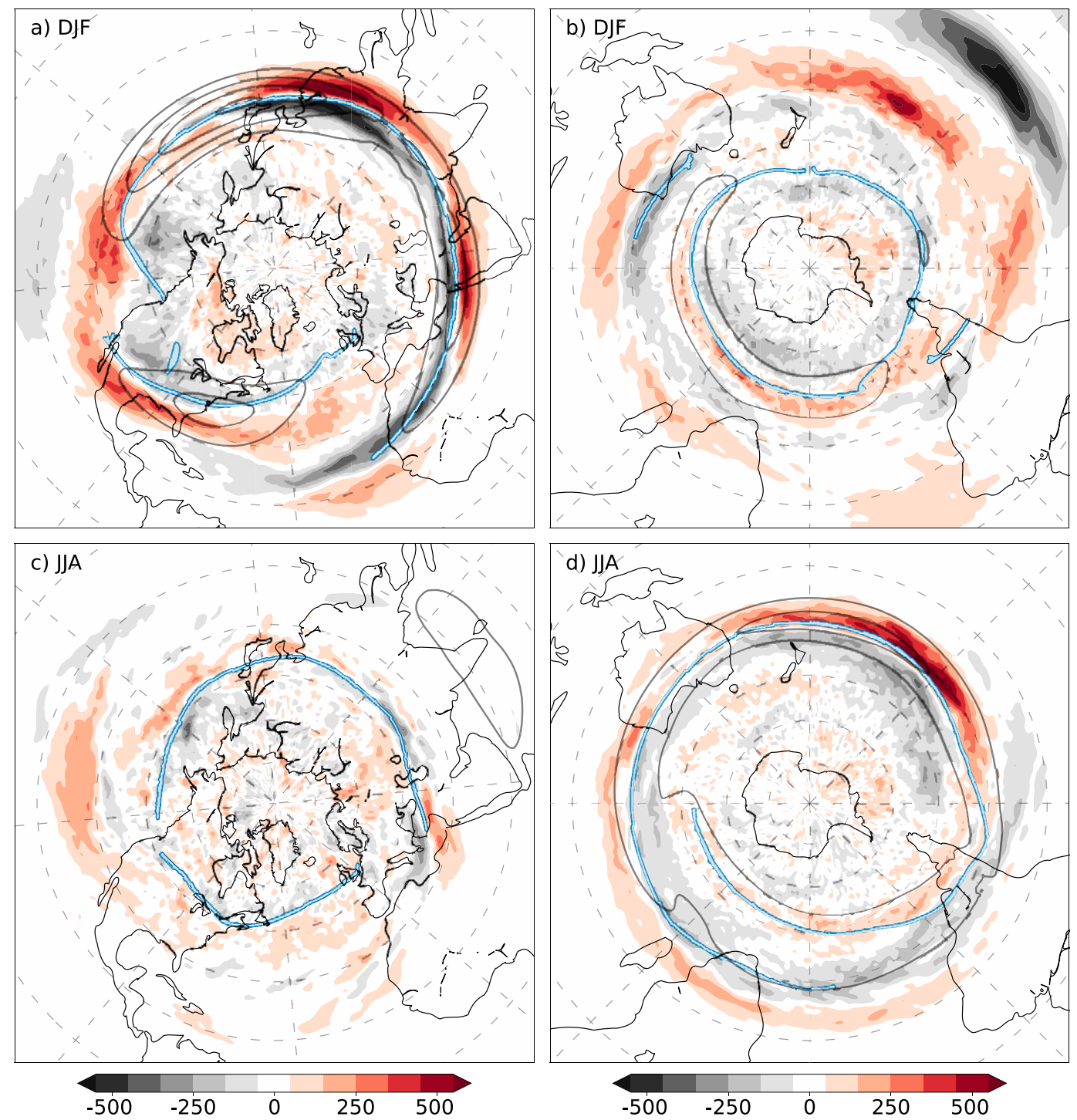

FIG. 15. Difference in the jet axis distribution [average line length; $\mathrm{km}(1000 \mathrm{~km})^{-2}$ ] between the positive and negative phases of the multivariate ENSO index (MEI.v2; Zhang et al. 2019) for (a),(b) DJF and (c),(d) JJA for the (left) Northern and (right) Southern Hemisphere. Black contours show the winter mean wind speed with an interval of $10 \mathrm{~m} \mathrm{~s}^{-1}$ starting at $30 \mathrm{~m} \mathrm{~s}^{-1}$, and the blue-white lines connect maxima in the seasonal jet axis distribution.

Despite these parallels, the pulsing tripole in response to the MJO is considerably more focused than that in response to ENSO (Figs. 15a and 16a). The response to the MJO is comparable in scale to the PNA, but is focused more on the east Pacific (Figs. 7d,e). Consistent with the results of Moore et al. (2010) and Henderson et al. (2016), this indicates a clear tendency toward the positive phase of the PNA during amplified tropical convection in the Pacific sector. Conversely, the undulating or double-jet structure in the eastern half of the North Pacific is related to amplified convection over the eastern Indian Ocean, which is consistent with the simultaneously increased frequency of blocks in the eastern North Pacific (Moore et al. 2010; Henderson et al. 2016).

Similar to ENSO, the strongest signal in the Southern Hemisphere summer is associated with the modulation of the occurrence of the westerly duct (Fig. 16b). In the subtropics and midlatitudes, the signal is less coherent with only a weak tendency for a latitudinal shift of the subtropical jet around Australia. During austral winter, however, the signal associated with the westerly duct disappears and the signal associated with the subtropical jet sharpens (Fig. 16d). The subtropical jet is located more equatorward over Australia and the western Pacific during phase 3 than during phase 7 of the MJO. 

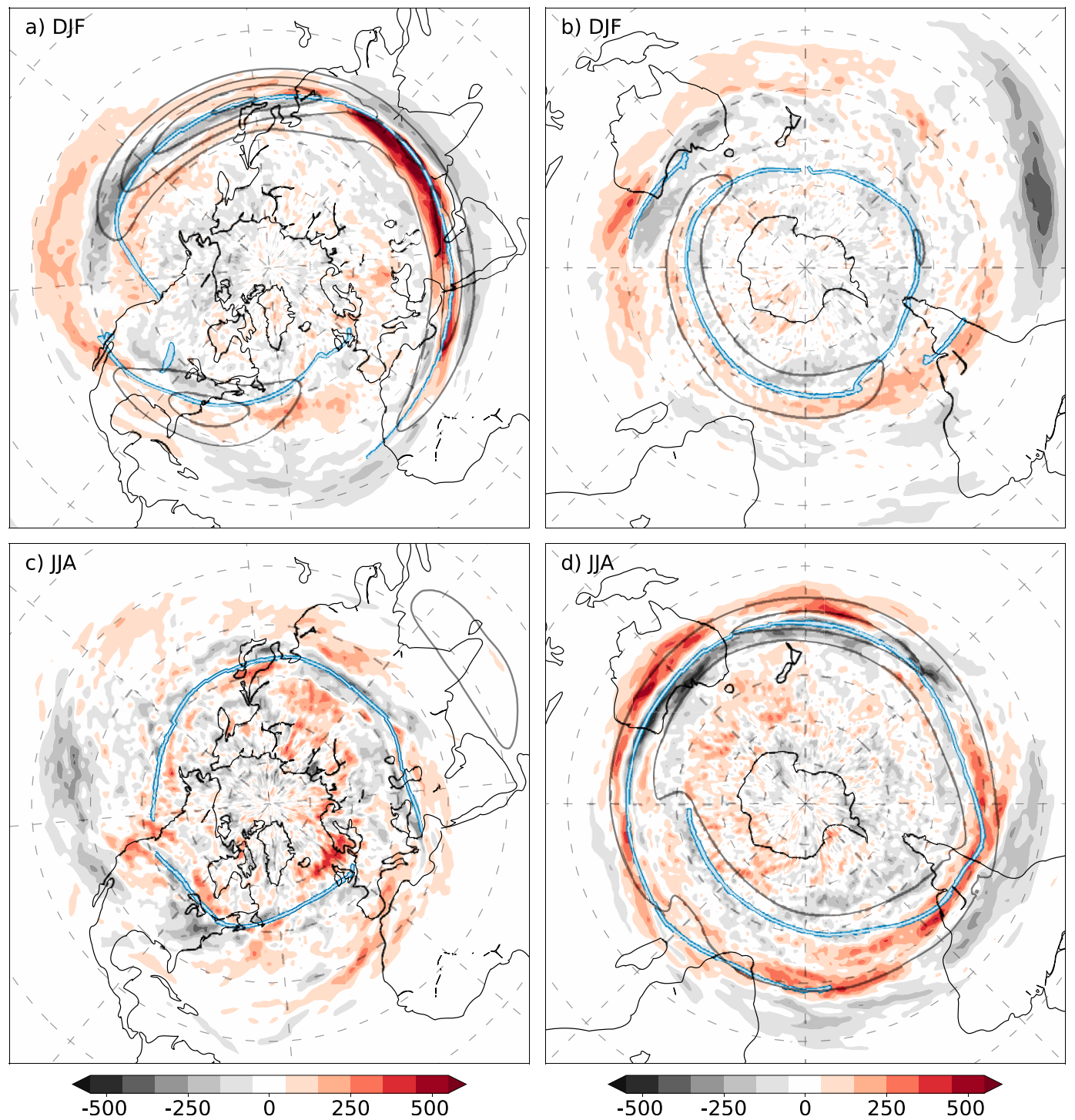

FIG. 16. As in Fig. 15, but for phase 3 minus phase 7 of MJO index of Wheeler and Hendon (2004).

In addition, there is a tendency for a more poleward location of the subtropical jet in the eastern Pacific and the South Atlantic sector (Fig. 16d). Together, these latitudinal shifts in opposite direction and at opposite longitudes suggest an overall displacement of the annular westerly circulation around Antarctica toward or away from the Australian sector.

Despite the clear parallels in the spatial structures associated with the jet response to ENSO and the MJO, the hemispheres differ in the sign of the response. In the Northern Hemisphere, the response to ENSO is most similar to MJO phase 7 with a reversed sign in Fig. 16a compared to Fig. 15a. In contrast, the jet response to ENSO in the Southern Hemisphere is most similar to MJO phase 3 (Figs. 15b,d and 16b,d). Forcing-wise,
$\mathrm{ENSO}^{+}$is similar to MJO phase 7 , as both are associated with increased convection in the central tropical Pacific as well as decreased convection over the eastern Indian Ocean and Maritime Continent. The similarities in forcing most likely explain the similarities in the northern hemispheric response to ENSO and the MJO. The antisymmetry documented for the Southern Hemisphere, however, cannot be explained that way.

Studies relating the MJO and the Southern Hemisphere storm track are unfortunately comparatively scarce. Fukutomi and Yasunari (2014) investigated the effect of the storm track over the south Indian Ocean on the initiation of MJO events, but we are not aware of any studies considering effects of the MJO on the Southern Hemisphere storm track. The presented 
discrepancies in the Southern Hemispheric response to the MJO and ENSO call for a more systematic investigation of tropical-extratropical interactions in both hemispheres.

\section{Conclusions}

We presented a climatology as well as the variability of jets based on an automated detection scheme for jet axes. Although closely related, jet axes differ from most diagnostics of the storm track in that they provide a simultaneous view on both the eddy-driven and subtropical jet.

In the midlatitudes, the climatology and seasonal cycle of the jet axis distribution are broadly consistent with those of other storm track diagnostics. In line with earlier findings, the spiraliform structure of the storm tracks indicated by the jet axes suggests a gradual transition of initially subtropical jets toward more and more eddydriven jets in conjunction with their poleward propagation. Rather than distinct categories, it might thus be more appropriate to regard the eddy-driven and subtropical archetypes as two limits in a spectrum of possible jet types.

In the Northern Hemisphere, jet axis-based variability is consistent with canonical geopotential-based variability patterns as well as the variability of common storm track diagnostics. Despite the consistency between the geopotential and jet axis-based perspectives, the latter indicates some novel aspects about Northern Hemisphere variability. First, the midlatitude jet variability described by the NAO and the EA is associated with variability of the North African subtropical jet. This covariability of the subtropical jet extends downstream all the way to East Asia. Second, with the exception of the PNA, none of the Northern Hemisphere variability patterns can be uniquely associated with either a latitudinal shifting or a pulsing type of jet variability. In contrast, the NAO and WP change in character from a latitudinal shifting-type variability toward a pulsingtype variability across the respective ocean basins. Analogously, the EA represents predominantly pulsing in the western Atlantic, but predominantly shifting in the eastern Atlantic. Consequently, it seems unlikely that any of the NAO, EA, or WP patterns can be strictly associated with either eddy or tropical driving.

We identified a rather weak correspondence between jet axis and geopotential variability in the Southern Hemisphere. During winter, we only found consistent patterns for the dominant modes of variability in the South Pacific and, to a lesser extent, in the south Indian Ocean. The South Pacific mode of variability is structurally very similar to both the NAO and the WP.
During summer, we identified patterns in the South Atlantic and south Indian Ocean, respectively, that might be related to SAM. We however found no equivalent in the South Pacific, which calls into question either the association of SAM with these patterns or the annular nature of summer SAM.

Finally, we showed how tropical variability associated with ENSO and the MJO modulates the jet distribution in both hemispheres. For the Northern Hemisphere, our results are in line with previous analyses and highlight interactions between the tropics and the subtropical jet over Asia and the North Pacific. The imprint of tropical variability on the jet can, however, be markedly different in the Southern Hemisphere. For example, during MJO phase 3, the jet is deflected poleward over Africa and Asia during boreal winter compared to phase 7, whereas it is deflected equatorward over Australia during austral winter.

Overall, our analyses call for further investigation of, in particular, the Southern Hemisphere storm track. Both sector-wise storm track variability and the interaction with the tropics exhibit marked differences compared to the Northern Hemisphere, and appear so far largely unexplored. Further, EOF analyses appear to be considerably less likely to yield physically meaningful results in the Southern Hemisphere than in the Northern Hemisphere. We might thus need new approaches to better characterize the southern storm track in order to gain a better dynamical understanding.

Acknowledgments. We thank Fumiaki Ogawa for insightful discussions and Camille Li for comments on an earlier version of this manuscript. We thank Gloria Manney and two anonymous reviewers for very detailed and constructive criticism that considerably helped to improve the presentation of the results. We thank ECMWF for providing the ERA-Interim data. The ERA-Interim data used in this study were obtained directly through the Meteorological Archival and Retrieval System.

\section{REFERENCES}

Afargan, H., and Y. Kaspi, 2017: A midwinter minimum in North Atlantic storm track intensity in years of a strong jet. Geophys. Res. Lett., 44, 12 511-12 518, https://doi.org/10.1002/2017GL075136.

Ambaum, M. H. P., B. J. Hoskins, and D. B. Stephenson, 2001: Arctic Oscillation or North Atlantic Oscillation? J. Climate, 14, 3495-3507, https://doi.org/10.1175/15200442(2001)014<3495:AOONAO > 2.0.CO 2 .

Archer, C. L., and K. Caldeira, 2008: Historical trends in the jet streams. Geophys. Res. Lett., 35, L08803, https://doi.org/ 10.1029/2008GL033614.

Athanasiadis, P. J., J. M. Wallace, and J. J. Wettstein, 2010: Patterns of wintertime jet stream variability and their relation 
to the storm tracks. J. Atmos. Sci., 67, 1361-1381, https:// doi.org/10.1175/2009JAS3270.1.

Barnes, E. A., and D. L. Hartmann, 2012: Detection of Rossby wave breaking and its response to shifts of the midlatitude jet with climate change. J. Geophys. Res., 117, D09117, https:// doi.org/10.1029/2012JD017469.

Chang, E. K. M., S. Lee, and K. L. Swanson, 2002: Storm track dynamics. J. Climate, 15, 2163-2183, https://doi.org/10.1175/ 1520-0442(2002)015<02163:STD >2.0.CO;2.

Davies, H. C., C. Schär, and H. Wernli, 1991: The palette of fronts and cyclones within a baroclinic wave development. J. Atmos. Sci., 48, 1666-1689, https://doi.org/10.1175/1520-0469(1991) 048<1666:TPOFAC $>2.0$.CO;2.

Dee, D. P., and Coauthors, 2011: The ERA-Interim reanalysis: Configuration and performance of the data assimilation system. Quart. J. Roy. Meteor. Soc., 137, 553-597, https://doi.org/ 10.1002/qj.828.

Eichelberger, S. J., and D. L. Hartmann, 2007: Zonal jet structure and the leading mode of variability. J. Climate, 20, 5149-5163, https://doi.org/10.1175/JCLI4279.1.

Francis, J. A., 2017: Why are Arctic linkages to extreme weather still up in the air? Bull. Amer. Meteor. Soc., 98, 2551-2557, https://doi.org/10.1175/BAMS-D-17-0006.1.

Fukutomi, Y., and T. Yasunari, 2014: Extratropical forcing of tropical wave disturbances along the Indian Ocean ITCZ. J. Geophys. Res. Atmos., 119, 1154-1171, https://doi.org/ 10.1002/2013JD020696.

Gallego, D., P. Ribera, R. Garcia-Herrera, E. Hernandez, and L. Gimeno, 2005: A new look for the Southern Hemisphere jet stream. Climate Dyn., 24, 607-621, https://doi.org/10.1007/ s00382-005-0006-7.

Grams, C. M., R. Beerli, S. Pfenninger, I. Staffell, and H. Wernli, 2017: Balancing Europe's wind-power output through spatial deployment informed by weather regimes. Nat. Climate Change, 7, 557-562, https://doi.org/10.1038/nclimate3338.

Hall, A., and M. Visbeck, 2002: Synchronous variability in the Southern Hemisphere atmosphere, sea ice, and ocean resulting from the annular mode. J. Climate, 15, 3043-3057, https://doi.org/10.1175/1520-0442(2002)015<3043:SVITSH> 2.0.CO;2.

Henderson, S. A., E. D. Maloney, and E. A. Barnes, 2016: The influence of the Madden-Julian oscillation on Northern Hemisphere winter blocking. J. Climate, 29, 4597-4616, https://doi.org/10.1175/JCLI-D-15-0502.1.

Hoskins, B. J., and T. Ambrizzi, 1993: Rossby wave propagation on a realistic longitudinally varying flow. J. Atmos. Sci., 50, 1661-1671, https://doi.org/10.1175/1520-0469(1993)050<1661: RWPOAR $>2.0 . \mathrm{CO} ; 2$.

Koch, P., H. Wernli, and H. C. Davies, 2006: An event-based jetstream climatology and typology. Int. J. Climatol., 26, 283-301, https://doi.org/10.1002/joc.1255.

Lau, K.-M., P.-J. Sheu, and I.-S. Kang, 1994: Multiscale lowfrequency circulation modes in the global atmosphere. J. Atmos. Sci., 51, 1169-1193, https://doi.org/10.1175/15200469(1994)051<1169:MLFCMI>2.0.CO;2.

Lau, N.-C., 1988: Variability of the observed midlatitude storm tracks in relation to low-frequency changes in the circulation pattern. J. Atmos. Sci., 45, 2718-2743, https://doi.org/10.1175/ 1520-0469(1988)045<2718:VOTOMS>2.0.CO;2.

Lee, S., and H. Kim, 2003: The dynamical relationship between subtropical and eddy-driven jets. J. Atmos. Sci., 60, 1490-1503, https://doi.org/10.1175/1520-0469(2003)060<1490:TDRBSA $>$ 2.0.CO;2.
Li, C., and J. J. Wettstein, 2012: Thermally driven and eddy-driven jet variability in reanalysis. J. Climate, 25, 1587-1596, https:// doi.org/10.1175/JCLI-D-11-00145.1.

Limbach, S., E. Schömer, and H. Wernli, 2012: Detection, tracking and event localization of jet stream features in 4-D atmospheric data. Geosci. Model Dev., 5, 457-470, https://doi.org/ 10.5194/gmd-5-457-2012.

Limpasuvan, V., and D. L. Hartmann, 1999: Eddies and the annular modes of climate variability. Geophys. Res. Lett., 26, 3133 3136, https://doi.org/10.1029/1999GL010478.

Lindzen, R. S., and B. Farrell, 1980: A simple approximate result for the maximum growth rate of baroclinic instabilities. J. Atmos. Sci., 37, 1648-1654, https://doi.org/10.1175/15200469(1980)037<1648:ASARFT>2.0.CO;2.

Lorenz, E. N., 1955: Available potential energy and the maintenance of the general circulation. Tellus, 7, 157-167, https:// doi.org/10.3402/tellusa.v7i2.8796.

Manney, G. L., and M. I. Hegglin, 2018: Seasonal and regional variations of long-term changes in upper-tropospheric jets from reanalyses. J. Climate, 31, 423-448, https://doi.org/ 10.1175/JCLI-D-17-0303.1.

— troposphere/lower stratosphere (UTLS): Applications to climatology and transport studies. Atmos. Chem. Phys., 11, 61156137, https://doi.org/10.5194/acp-11-6115-2011.

— M. I. Hegglin, W. H. Daffer, M. J. Schwartz, M. L. Santee, and S. Pawson, 2014: Climatology of upper tropospheric-lower stratospheric (UTLS) jets and tropopauses in MERRA. J. Climate, 27, 3248-3271, https://doi.org/10.1175/JCLI-D-1300243.1.

— , and Coauthors, 2017: Reanalysis comparisons of upper tropospheric-lower stratospheric jets and multiple tropopauses. Atmos. Chem. Phys., 17, 11 541-11566, https://doi.org/ 10.5194/acp-17-11541-2017.

Martius, O., C. Schwierz, and H. C. Davies, 2010: Tropopause-level waveguides. J. Atmos. Sci., 67, 866-879, https://doi.org/ 10.1175/2009JAS2995.1.

Moore, R. W., O. Martius, and T. Spengler, 2010: The modulation of the subtropical and extratropical atmosphere in the Pacific basin in response to the Madden-Julian oscillation. Mon. Wea. Rev., 138, 2761-2779, https://doi.org/10.1175/2010MWR3194.1.

Nakamura, H., 1992: Midwinter suppression of baroclinic wave activity in the Pacific. J. Atmos. Sci., 49, 1629-1642, https://doi.org/ 10.1175/1520-0469(1992)049<1629:MSOBWA > 2.0.CO;2.

Neu, U., and Coauthors, 2013: IMILAST: A community effort to intercompare extratropical cyclone detection and tracking algorithms. Bull. Amer. Meteor. Soc., 94, 529-547, https:// doi.org/10.1175/BAMS-D-11-00154.1.

Ogawa, F., H. Nakamura, K. Nishii, T. Miyasaka, and A. KuwanoYoshida, 2016: Importance of midlatitude oceanic frontal zones for the annular mode variability: Interbasin differences in the southern annular mode signature. J. Climate, 29, 61796199, https://doi.org/10.1175/JCLI-D-15-0885.1.

O'Kane, T. J., D. P. Monselesan, and J. S. Risbey, 2017: A multiscale reexamination of the Pacific-South American pattern. Mon. Wea. Rev., 145, 379-402, https://doi.org/10.1175/MWR-D-16-0291.1.

Pena-Ortiz, C., D. Gallego, P. Ribera, P. Ordonez, and M. D. C. Alvarez-Castro, 2013: Observed trends in the global jet stream characteristics during the second half of the 20th century. J. Geophys. Res. Atmos., 118, 2702-2713, https://doi.org/ 10.1002/jgrd.50305.

Reboita, M. S., R. P. da Rocha, T. Ambrizzi, and S. Sugahara, 2010: South Atlantic Ocean cyclogenesis climatology simulated by 
regional climate model (RegCM3). Climate Dyn., 35, 13311347, https://doi.org/10.1007/s00382-009-0668-7.

Renwick, J. A., and J. M. Wallace, 1996: Relationships between North Pacific wintertime blocking, El Niño, and the PNA pattern. Mon. Wea. Rev., 124, 2071-2076, https://doi.org/ 10.1175/1520-0493(1996)124<2071:RBNPWB>2.0.CO;2.

Rivière, G., 2009: Effect of latitudinal variations in low-level baroclinicity on eddy life cycles and upper-tropospheric wavebreaking processes. J. Atmos. Sci., 66, 1569-1592, https:// doi.org/10.1175/2008JAS2919.1.

Schemm, S., L. M. Ciasto, C. Li, and N. G. Kvamst $\varnothing$, 2016: Influence of tropical Pacific sea surface temperature on the genesis of Gulf Stream cyclones. J. Atmos. Sci., 73, 4203-4214, https://doi.org/10.1175/JAS-D-16-0072.1.

_ , G. Riviére, L. M. Ciasto, and C. Li, 2018: Extratropical cyclogenesis changes in connection with tropospheric ENSO teleconnections to the North Atlantic: Role of stationary and transient waves. J. Atmos. Sci., 75, 3943-3964, https://doi.org/ 10.1175/JAS-D-17-0340.1.

Souders, M. B., B. A. Colle, and E. K. M. Chang, 2014: The climatology and characteristics of Rossby wave packets using a feature-based tracking technique. Mon. Wea. Rev., 142, 35283548, https://doi.org/10.1175/MWR-D-13-00371.1.

Spensberger, C., T. Spengler, and C. Li, 2017: Upper-tropospheric jet axis detection and application to the boreal winter 2013/14 . Mon. Wea. Rev., 145, 2363-2374, https://doi.org/10.1175/ MWR-D-16-0467.1.

- - M. J. Reeder, T. Spengler, and M. Patterson, 2020: Connection between the southern annular mode and a feature-based perspective on Southern Hemisphere midlatitude winter variability. J. Climate, 33, 115-129, https:// doi.org/10.1175/JCLI-D-19-0224.1.

Strong, C., and R. E. Davis, 2008: Variability in the position and strength of winter jet stream cores related to Northern Hemisphere teleconnections. J. Climate, 21, 584-592, https:// doi.org/10.1175/2007JCLI1723.1.

- , and G. Magnusdottir, 2008: Tropospheric Rossby wave breaking and the NAO/NAM. J. Atmos. Sci., 65, 2861-2876, https://doi.org/10.1175/2008JAS2632.1.

Thompson, D. W. J., and J. D. Woodworth, 2014: Barotropic and baroclinic annular variability in the Southern Hemisphere. J. Atmos. Sci., 71, 1480-1493, https://doi.org/10.1175/JAS-D-13-0185.1.

Thorncroft, C. D., B. J. Hoskins, and M. E. McIntyre, 1993: Two paradigms of baroclinic-wave life-cycle behaviour. Quart.
J. Roy. Meteor. Soc., 119, 17-55, https://doi.org/10.1002/qj. 49711950903.

Van Meerbeeck, C. J., H. Renssen, and D. M. Roche, 2009: How did marine isotope stage 3 and Last Glacial Maximum climates differ?-Perspectives from equilibrium simulations. Climate Past, 5, 33-51, https://doi.org/10.5194/cp-5-33-2009.

Walker, G., and E. W. Bliss, 1932: World weather V. Mem. Roy. Meteor. Soc., 4, 53-84.

Wallace, J. M., and D. S. Gutzler, 1981: Teleconnections in the geopotential height field during the Northern Hemisphere winter. Mon. Wea. Rev., 109, 784-812, https://doi.org/10.1175/ 1520-0493(1981)109<0784:TITGHF>2.0.CO;2.

Waugh, D. W., and L. M. Polvani, 2000: Climatology of intrusions into the tropical upper troposphere. Geophys. Res. Lett., 27, 3857-3860, https://doi.org/10.1029/2000GL012250.

Webster, P. J., and J. R. Holton, 1982: Cross-equatorial response to middle-latitude forcing in a zonally varying basic state. J. Atmos. Sci., 39, 722-733, https://doi.org/10.1175/15200469(1982)039<0722:CERTML>2.0.CO;2.

Wettstein, J. J., and J. M. Wallace, 2010: Observed patterns of month-to-month storm-track variability and their relationship to the background flow. J. Atmos. Sci., 67, 1420-1437, https:// doi.org/10.1175/2009JAS3194.1.

Wheeler, M. C., and H. H. Hendon, 2004: An all-season real-time multivariate MJO index: Development of an index for monitoring and prediction. Mon. Wea. Rev., 132, 1917-1932, https://doi.org/10.1175/1520-0493(2004)132<1917:AARMMI> 2.0.CO;2.

Williams, L. N., S. Lee, and S.-W. Son, 2007: Dynamics of the Southern Hemisphere spiral jet. J. Atmos. Sci., 64, 548-563, https://doi.org/10.1175/JAS3939.1.

Wirth, V., M. Riemer, E. K. M. Chang, and O. Martius, 2018: Rossby wave packets on the midlatitude waveguide-A review. Mon. Wea. Rev., 146, 1965-2001, https://doi.org/10.1175/ MWR-D-16-0483.1.

Woollings, T., A. Hannachi, and B. Hoskins, 2010: Variability of the North Atlantic eddy-driven jet stream. Quart. J. Roy. Meteor. Soc., 136, 856-868, https://doi.org/10.1002/qj.625.

— and Coauthors, 2018: Daily to decadal modulation of jet variability. J. Climate, 31, 1297-1314, https://doi.org/10.1175/JCLI-D-17-0286.1.

Zhang, T., A. Hoell, J. Perlwitz, J. Eischeid, D. Murray, M. Hoerling, and T. M. Hamill, 2019: Towards probabilistic multivariate ENSO monitoring. Geophys. Res. Lett., 46, 10532 10 540, https://doi.org/10.1029/2019GL083946. 